\title{
Sustainable Development Goals relevant to kidney health: an update on progress
}

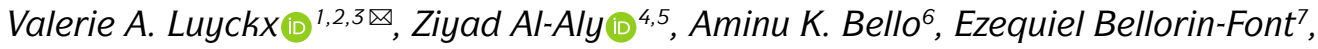
Raul G. Carlini ${ }^{8}$, June Fabian $\mathbb{1 0}^{9}$, Guillermo Garcia-Garcia ${ }^{10}{ }^{10}$, Arpana Iyengar ${ }^{11}$, Mohammed Sekkarie ${ }^{12}$, Wim van Biesen (1) ${ }^{13}$, Ifeoma Ulasi ${ }^{14}$, Karen Yeates ${ }^{15}$ and John Stanifer ${ }^{16}$

Abstract | Globally, more than 5 million people die annually from lack of access to critical treatments for kidney disease - by 2040, chronic kidney disease is projected to be the fifth leading cause of death worldwide. Kidney diseases are particularly challenging to tackle because they are pathologically diverse and are often asymptomatic. As such, kidney disease is often diagnosed late, and the global burden of kidney disease continues to be underappreciated. When kidney disease is not detected and treated early, patient care requires specialized resources that drive up cost, place many people at risk of catastrophic health expenditure and pose high opportunity costs for health systems. Prevention of kidney disease is highly cost-effective but requires a multisectoral holistic approach. Each Sustainable Development Goal (SDG) has the potential to impact kidney disease risk or improve early diagnosis and treatment, and thus reduce the need for high-cost care. All countries have agreed to strive to achieve the SDGs, but progress is disjointed and uneven among and within countries. The six SDG Transformations framework can be used to examine SDGs with relevance to kidney health that require attention and reveal inter-linkages among the SDGs that should accelerate progress.

"Globalization was purported to be the rising tide that would lift all boats. However, the reality has been that it lifted the big boats but tended to sink or swamp many smaller ones", Margaret Chan, World Conference on Social Determinants of Health, 2011 (REF. ${ }^{1}$ ).

Healthy people, living healthy lives on a healthy and peaceful planet - these are the ultimate objectives of the 17 Sustainable Development Goals (SDGs), which were formally adopted by all United Nations member states in 2015, to be achieved by 2030 (REF.'). The SDGs highlight that achieving health and well-being for all requires a robust, multisectoral approach.

Kidney disease is often a consequence of, or is exacerbated by, the lack of access to primary health care, early diagnosis and essential medications. Consequently, kidney disease disproportionately affects vulnerable populations and exacerbates poverty. Kidney dysfunction is also associated with a high cost of care and is a major contributor to morbidity and mortality, although this effect is often obscured by its comorbid diseases ${ }^{3}$. Approximately 850 million people worldwide are estimated to have kidney disease, including chronic kidney disease (CKD), acute kidney injury (AKI) and kidney failure, for which patients require kidney replacement therapy (KRT) - dialysis or kidney transplantation for survival ${ }^{4}$. Lack of access to dialysis has long been a reality in low-income countries (LICs), but its impact has now been dramatically highlighted even in high-income countries (HICs), owing to critical shortages of dialysis equipment and staff during the coronavirus disease 2019 (COVID-19) pandemic ${ }^{5}$. CKD is the leading cause of catastrophic health expenditure (that is, out-of-pocket expenditure on health above $40 \%$ of household income that further impoverishes the household) worldwide ${ }^{6}$. Global mortality from kidney disease might be as high as 5 million annually, given the widespread lack or limited access to life-saving $\mathrm{KRT}^{3,7,8}$. CKD is projected to become the world's fifth leading cause of death by 2040 (REF. ${ }^{9}$ ).

The recognition that health is key to maximizing our individual capabilities underscores the importance of ensuring that the SDGs do not become perpetual targets but instead become realized goals, leaving no one behind ${ }^{10}$ (BOX 1). In this Review, we outline the relevance 


\begin{abstract}
Key points
- Each Sustainable Development Goal (SDG) has the potential to improve kidney health and prevent kidney disease by improving the general health and well-being of individuals and societies, and by protecting the environment.

- Achievement of each SDG is interrelated to the achievement of multiple other SDGs; therefore, a multisectoral approach is required.

- The global burden of kidney disease has been relatively underestimated because of a lack of data.

- Structural violence and the social determinants of health have an important impact on kidney disease risk.

- Kidney disease is the leading global cause of catastrophic health expenditure, in part because of the high costs of kidney replacement therapy.

- Achievement of universal health coverage is the minimum requirement to ensure sustainable and affordable access to early detection and quality treatment of kidney disease and/or its risk factors, which should translate to a reduction in the burden of kidney failure in the future.
\end{abstract}

\section{Vertical programmes}

Disease-specific programmes that may not be integrated within the health system, are often driven independently by external funding and may undermine the health system.

Horizontal approaches Programmes that incorporate multiple diseases or programmes within the health system, which are generally integrated into and paid for by the health system. of the SDGs for non-communicable diseases (NCDs) ${ }^{11}$ as a whole, and for kidney health and disease in particular. In 2020, five years after the launch of the SDGs, with ten years still to come, we use the six SDG transformations as a framework to discuss current progress and remaining challenges. A more detailed discussion of how each SGD might impact the risk of specific kidney disorders is found elsewhere ${ }^{3}$.

\section{Sustainable Development Goals}

The SDGs succeeded the Millennium Development Goals (MDGs), which were in place from 2000 to 2015 $\left(\right.$ REF $\left.^{12}\right)$. The MDGs introduced a common goal of reducing poverty through improved governance and accountability. Global progress was achieved, with an estimated 21-29.7 million lives saved and 471 million fewer people living in extreme poverty ${ }^{13,14}$ (Supplementary Table 1).

\footnotetext{
Author addresses

${ }^{1}$ Renal Division, Brigham and Women's Hospital, Harvard Medical School, Boston, MA, USA. 2Department of Paediatrics and Child Health, University of Cape Town, Cape Town, South Africa.

${ }^{3}$ Institute of Biomedical Ethics and the History of Medicine, University of Zürich, Zürich, Switzerland.

${ }^{4}$ Department of Medicine, Washington University in Saint Louis, Saint Louis, MO, USA ${ }^{5}$ Clinical Epidemiology Center, Veterans Affairs Saint Louis Health Care System, Saint Louis, MO, USA

${ }^{6}$ Division of Nephrology \& Immunology, Faculty of Medicine \& Dentistry, University of Alberta, Edmonton, Alberta, Canada.

${ }^{7}$ Division of Nephrology, Saint Louis University, Saint Louis, MO, USA.

${ }^{8}$ Sección de Investigación, Servicio de Nefrología y Trasplante Renal, Hospital

Universitario de Caracas, Caracas, Venezuela.

${ }^{9}$ Wits Donald Gordon Medical Centre, School of Clinical Medicine, Faculty of Health Sciences, University of the Witwatersrand, Witwatersrand, South Africa.

${ }^{10}$ Nephrology Service, Hospital Civil de Guadalajara Fray Antonio Alcalde, University of

Guadalajara Health Sciences Center, Hospital, 278, Guadalajara, Mexico.

${ }^{11}$ Department of Paediatric Nephrology, St. John's National Academy of Health Sciences, Bangalore, India.

${ }^{12}$ Nephrology and Hypertension Associates, Bluefield, WV, USA.

${ }^{13}$ Renal Division, Ghent University Hospital, Ghent, Belgium.

${ }^{14}$ Renal Unit, Department of Medicine, University of Nigeria Teaching Hospital, Enugu, Nigeria.

${ }^{15}$ Division of Nephrology, Department of Medicine, Queen's University, Kingston, Ontario, Canada.

${ }^{16}$ Munson Nephrology, Munson Healthcare, Traverse City, MI, USA.
}

Weaknesses of the MDGs included the focus on outcomes, rather than on systematic strengthening of the processes required to achieve those outcomes, and insufficient focus on addressing structural risk factors and achieving social justice ${ }^{15}$. The MDGs focused primarily on 'priority' needs of 'developing countries', relying heavily on external development aid. Narrow health targets led to the development of disease-specific vertical programmes (for HIV/AIDS, tuberculosis and malaria), and maternal and child health. These programmes achieved gains but risked weakening health systems and diverted funds away from non-target programmes ${ }^{16,17}$.

The SDGs evolved to incorporate economic, social and environmental dimensions, with an emphasis on five crucial areas - people (SDGs 1-6), planet (SDGS 13-15), prosperity (SDGs 7-12), peace (SDG 16) and partnerships (SDG 17) ${ }^{18}$ (Supplementary Table 2). The SDGs apply to all countries, emphasize the alignment of goals with country priorities, and focus on policy implementation and addressing climate change ${ }^{18}$. Context-specific 'systems thinking' is key to developing successful multisectoral strategies because many goals are interdependent. Of note, although all United Nations member states have signed on to the SDGs, achievement of the goals remains voluntary. The 17 goals comprise 169 targets, which require robust infrastructure and monitoring capacity $^{19,20}$. The overall SDG Index (range $0-100$ ) is an aggregate of the performance of a country across all 17 goals; this performance currently ranges from 39.1 (Central African Republic) to 85.2 (Denmark) ${ }^{19}$. More granular SDG-specific indices help to identify where attention is required ${ }^{20}$ (TABLE 1).

\section{Non-communicable diseases}

Global epidemiological trends show that mortality from communicable diseases has significantly declined, but mortality due to NCDs has risen in the past few decades. The SDGs reflect this shift and acknowledge the need to tackle NCDs, which were overlooked in the $\mathrm{MDGs}^{17,21}$. However, despite the recognition that NCDs are major contributors to global morbidity and mortality, action to tackle these diseases has remained slow ${ }^{11}$. The COVID-19 pandemic is highlighting the artificiality of the dichotomy between communicable and non-communicable diseases, and has reinforced the need to "Build Back Better" and strengthen health systems in the aftermath of COVID-19 by incorporating NCDs into health systems planning ${ }^{22}$ (BOX 2).

NCDs require complex, multi-level and horizontal approaches to diagnosis and management, functioning primary health-care and referral systems, and long timelines to measure progress ${ }^{21}$. Given the need for long-term sustainability, NCD programmes should be designed and funded by national governments. Since the launch of the NCD Action Plan, following the first UN high-level meeting on NCDs in 2008, global efforts have focused primarily on four NCDs - cardiovascular disease (CVD) and stroke, chronic respiratory disease, cancer and diabetes; mental health was added as a fifth NCD after the third high-level meeting on NCDs in 2018 (REF. ${ }^{11}$ ). Kidney disease has been neglected, in part because the burden has not been recognized (owing to 


\section{Box 1 | Visions on health from a Sustainable Development Goal perspective}

Exploring how the Sustainable Development Goals (SDGs) impact health, including kidney health, requires a clear definition of sustainable health. Deploying sustainable strategies to achieve non-sustainable health is illogical.

Health can be defined from two perspectives - naturalist or normative. The naturalist approach defines disease as a biological deviation from normal. Clear as this definition might seem, it is fraught with questions such as "what is normal?" (for example, glomerular filtration rate in older individuals), "how much deviation is abnormal?" (for example, stunted growth) and "is the deviation relevant?" (for example, simple kidney cysts). By contrast, the normative approach defines disease as any physical or psychological condition that impacts well-being. Both of these approaches affect what might be considered sustainable health care. According to the naturalist approach, only interventions that divert the disease course towards normal - predominantly surgery and medication - count as improving health. By contrast, the normative approach affirms that all interventions that improve holistic well-being, including confronting and tackling racism, sustainable food production, and access to clean water and education, can improve health.

In practice, both streams are important and complementary for achieving sustainable health. The SDGs predominantly address the normative definition of health, but also encompass the naturalist one. Education and clean environment, for example, can improve the health of the population on both levels. Emphasis on the naturalist view in Western cultures is spurred by industry, technology and the ideal of the Makeable Human (that is, human enhancement). This vision begins with curing disease rather than maintaining health, and results in non-sustainable health-care systems, as highlighted by the coronavirus disease 2019 crisis. The normative view might be the most important for the prevention of non-communicable diseases, which require complex and costly approaches to care. Encompassing both, the SDGs can promote kidney health in the population and thereby improve the chances of sustainable access to adequate care for those who develop kidney disease.

limited awareness and infrastructure for diagnosis), and because of the perception that (late-stage) kidney disease is too expensive to treat in $\mathrm{LICs}^{7,23,24}$.

SDGs and kidney health. As mentioned earlier, the MDGs delivered some successes, including global reductions in maternal, neonatal and child mortality, improved vaccine coverage, reduced the burden of HIV, malaria and tuberculosis, and reduced tobacco consumption $^{2,25}$ (Supplementary Table 1). These successes should positively impact kidney health ${ }^{26}$, although important ground is being lost in the current COVID-19 pandemic. The risk of premature death (that is, death of individuals aged 30-70 years) from NCDs has declined slightly overall, but progress is uneven. Between 1990 and 2017, global age-standardized mortality (ASM; deaths per 100,000 population) for CVD, cancer and chronic obstructive pulmonary disease declined by $30.4 \%$ (from 334.7 to 233.1 ), $14.9 \%$ (from 142.5 to 121.2 ) and $41.3 \%$ (from 89.5 to 51.4 ), respectively. However, CKD ASM has remained essentially unchanged increasing from 15.5 in 1990 to 15.9 in 2017 (REFS ${ }^{27,28}$ ). Of note, limited access to KRT is contributing to a rising fraction of deaths attributed to CKD in low-income settings ${ }^{27}$. Given the broad spectrum of physical and structural factors that affect the risk of kidney disease, all SDGs are relevant to kidney health ${ }^{3}$ (TABLE 2).

\section{Progress within SDG transformations}

No country is on track to achieve all SDGs ${ }^{19}$. Even in high-performing HICs, persistent inequities and insufficient attention to the environment persist (Supplementary Table 2). The Sustainable Development
Report of 2019 suggested that the SDGs can be better operationalized through six SDG transformations rather than a vertical focus on individual goals ${ }^{19}$ (TABLE 2). These transformations bring together multiple SDGs, each spanning multiple transformations, which synergize towards the overall goal of leaving no one behind ${ }^{19}$. Ministries of health should contribute to each transformation. The potential for progress towards better kidney health is discussed below using this framework, which illustrates the interconnectedness of many SDGs.

\section{Education, gender and inequality}

This transformation, which comprises SDGs 1, 5, 7-10, $12-15$ and 17, brings together ministries overseeing education, technology, social development and family affairs to positively impact early childhood development, education and social protection across the life course. This transformation will improve kidney health by ensuring a healthier start in life, improving equity and access to health promotion and care.

Education. Quality education (SDG 4) is fundamental to reducing inequality and poverty, and empowers people to live healthier lives ${ }^{25}$. Since the launch of the MDGs, the proportion of children enrolled in primary education has increased from $83 \%$ to $91 \%{ }^{25}$ (Supplementary Tables 1 and 2). This portends good news, as children of mothers who complete primary school are more likely to survive and education level positively correlates with health status; however, overall progress masks deepening inequities. In LICs, millions of children (more girls than boys) remain out of school, hundreds of millions of adults (predominantly women) remain illiterate, and many schools have neither adequately trained teachers, nor access to computers or the internet ${ }^{2}$. For numerous children, school is also a primary source of daily nutrition ${ }^{29}$. Concerningly, during the COVID-19 pandemic, reduced access to education has disproportionately affected students with limited financial resources ${ }^{26}$.

Education is also key for health literacy, which enhances the capacity of an individual to make healthy choices $^{30}$. Low health literacy is common in patients with kidney disease and has been associated with treatment failure and poor health outcomes, including death ${ }^{30,31}$. Education is also necessary to support the development of a future skilled workforce.

The potential benefits of enhanced professional and public education regarding kidney disease - for example, raising kidney health awareness and improving knowledge about risks of nephrotoxic medications - illustrate the importance of SDG4 for global kidney health. In Mexico, innovative technologies that combine community-based and household-based education with ongoing systematic professional education enabled earlier detection of CKD and improved outcomes ${ }^{32}$. Similarly, Thailand, Vietnam, Pakistan and Bangladesh are improving kidney health awareness and knowledge through multidisciplinary NCD care models built around community engagement, group counselling, capacity building and enhanced patient surveillance ${ }^{33-36}$.

In HICs, team-based care that includes clinical pharmacists and the use of automated electronic health 
Table 1 | SDG dashboard relevant for kidney health — South African example of selected indicators

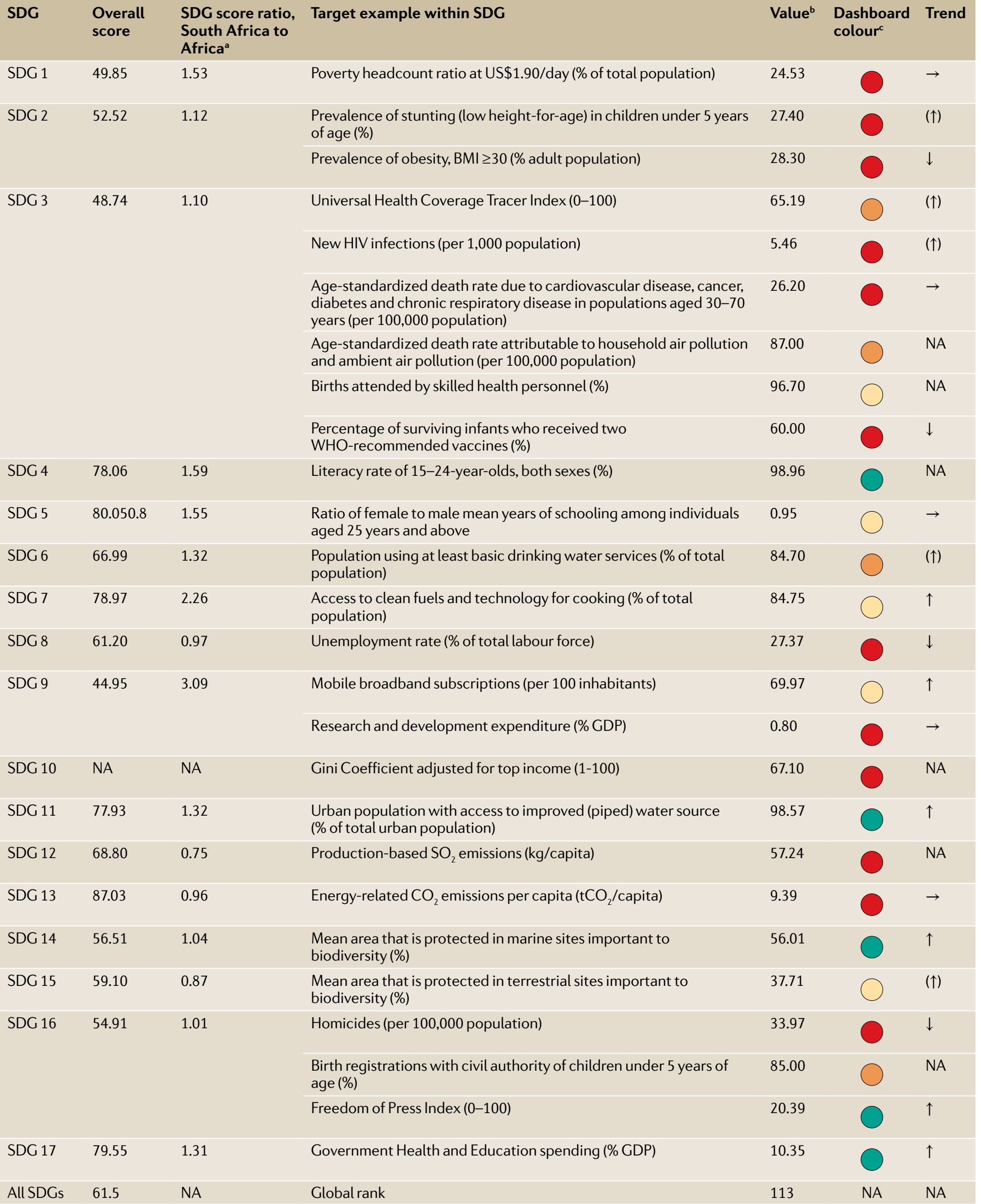

Data derived from REF. ${ }^{19}$. GDP, gross domestic product; NA, not available; SDG, Sustainable Development Goal; WHO, World Health Organization; $\uparrow$, on track or maintaining achievement; $(\uparrow)$, moderately increasing; $\rightarrow$, stagnating; $\downarrow$, decreasing. ${ }^{a}$ A ratio of $>1$ or $<1$ suggests that South Africa is performing better or worse than the African average, respectively. ${ }^{b}$ Value refers to the percent, rate or proportion relevant to each SDG in South Africa in 2019. 'Colour code - green, goal achieved; yellow, challenges remain; orange, substantial challenges remain; red, major challenges remain. 


\section{Ayurvedic medicine An Indian alternative therapeutic method that incorporates mind, body and spirit in healing practices using physical treatments (for example, massage and medicinal products)}

records that report estimated glomerular filtration rate (eGFR) have enhanced awareness of CKD and AKI, facilitated new patient surveillance efforts and reduced the number of adverse events caused by inappropriate drug dosing or the use nephrotoxic medications ${ }^{30,37-40}$. Such innovations can be rapidly implemented in HICs but the risk from nephrotoxic preparations is highest in LICs and middle-income countries (MICs) ${ }^{41}$, where it mostly affects young, otherwise healthy individuals ${ }^{42}$. In many lower-middle-income countries (LMICs), traditional and herbal medicines are the principal form of health care ${ }^{42}$. In India and China, the World Health Organization (WHO) has advocated for an 'integrative' approach that combines allopathic medicine (that is, conventional medicine) with Ayurvedic medicine and traditional Chinese medicine. However, substantial work is needed to engage with traditional healers and communities, and to better understand potential synergies and risks ${ }^{43,44}$.

Women and children's health in the context of gender and inequality. Gender equality (SDG 5) not only improves the health of women and children, but promotes economic growth and social change $e^{25,45}$. Access to primary school education for girls has improved, and rates of child marriage and female genital mutilation have decreased since 2000, but gender inequalities remain pervasive ${ }^{25,46}$. Women and girls remain at the greatest risk of poverty, food insecurity, violence, limited access to secondary education, unpaid or underpaid work, hazardous exposures and trafficking ${ }^{47}$.

\section{Box 2 | Structural violence, COVID-19 and racism}

The concept of structural violence was defined by Galtung in 1969 as the product of the avoidable failure to meet basic human needs ${ }^{186}$. Farmer and Marmot have since championed this concept, highlighting how poverty, disenfranchisement, lack of opportunity and the social gradient exacerbate inequities and make health an insurmountable challenge for many ${ }^{187-189}$.

The coronavirus disease 2019 (COVID-19) pandemic ${ }^{5}$ and the concurrent global campaign against racism, led by the Black Lives Matter movement, urgently highlight the reality of this concept. An individual's legacy of racism and discrimination shapes their vulnerability. The individuals most susceptible to infection and severe illness from COVID-19 are those least able to defend themselves from it - individuals whose communities have been subjected to structural violence for decades and centuries ${ }^{190-192}$. Patients with pre-existing comorbidities, including kidney disease, which is often exacerbated by structural inequities, are at a high risk of death from COVID-19 (REF. ${ }^{193}$ ). Not only does COVID-19 represent an immediate threat to individual health, but the COVID-19 pandemic will indirectly affect future health by exacerbating poverty, hunger and inequality, disrupting education, diverting health-care resources away from other health conditions, and creating micro-economies where profiteering can flourish. However, this crisis should also lead to innovation, including approaches to improving pandemic preparedness and creating stronger health-care systems, as well as addressing structural violence, enhancing solidarity and understanding of end-of-life decision making. The WHO "Build Back Better" campaign ${ }^{22}$ highlights the necessity to carefully consider non-communicable diseases as health-care systems restructure post-pandemic.

The resource constraints experienced by high-income countries owing to the COVID-19 pandemic - for example, the need to ration medical supplies and equipment, which would typically be a dilemma reserved for $\mathrm{LICs}$ - as well as the widespread account of social injustices in the media, have boosted global awareness of social determinants of health. For nephrology professionals worldwide, this crisis is unfortunately familiar, as even under non-pandemic circumstances, kidney disease serves as a beacon of inequity, particularly in regions with limited resources. Now is the time to acknowledge and address global inequities that impede kidney health.
These risks have increased during the COVID-19 pandemic. Moreover, women hold fewer leadership positions, have fewer assets and, despite being important contributors to the health-care workforce, remain underrecognized contributors to the health and wealth of countries ${ }^{46}$

In many countries, women and children have reduced access to health care, in part owing to economic disenfranchisement, needing permission from males to seek care and having household responsibilities that may be difficult to delegate ${ }^{46,48}$. The problem is not limited to accessing health centres - essential medicines required for women and children (for example, to treat obstetric complications or antibiotics) are often not available ${ }^{49,50}$. The maternal mortality ratio (that is, maternal deaths per 100,000 live births) is the most inequitably distributed health indicator -1 woman dies for every 202 live births in LICs compared with 1 in 5,900 in $\mathrm{HICs}^{51}$. These deaths can be prevented by optimizing the health of girls and women, improving access to contraception, birth spacing and providing high-quality ante-natal and peri-partum care ${ }^{51}$. Maternal mortality has decreased globally by $37 \%$ since 2000 , likely reflecting more skilled birth attendance, but the incidence of pregnancy-related complications such as pre-eclampsia has not improved, which creates additional morbidities among women survivors, including hypertension and $\mathrm{CKD}^{25,52}$.

In $2015,77 \%$ of deaths in women were attributable to $\mathrm{NCDs}^{53}$. Gender-related inequities place women at risk of kidney disease. Adolescent girls in sub-Saharan Africa are three times more likely than adolescent boys to become infected with HIV, an important risk factor for kidney disease. Overall, adolescent birth rates have declined but remain eight times higher in LICs compared with $\mathrm{HICs}^{51}$. Adolescent pregnancies are associated with higher rates of pre-eclampsia, preterm birth and low birthweight. These pregnancy outcomes are influenced by maternal education, pre-pregnancy health and nutrition, and are associated with an increase in the future risk of hypertension and CKD in both the mother and the child ${ }^{54}$. Globally, the proportion of women receiving KRT is also lower than that of men, in part because women have reduced access to care and ability to pay ${ }^{55,56}$. Further, women receiving dialysis experience disproportionately worse outcomes, including cardiovascular death, than men ${ }^{27,57}$. Women are also globally more likely to be kidney donors and are sometimes pressured into organ donation by patriarchal families $^{58,59}$.

Children and adolescents are particularly vulnerable to the negative effects of social determinants of health, which determine their lifelong health and capabilities, and those of subsequent generations ${ }^{60}$ (FIG. 1). The SDGs represent a paradigm shift that highlights dimensions of children's rights beyond health - the right to survive and thrive, learn, be protected from violence and exploitation, live in safe and clean environments, and have a fair chance in life ${ }^{60,61}$. Globally, in 2017, 168 million children were engaged in child labour, including slavery, which robs them of their childhoods and exposes them to health risks ${ }^{62}$. 
Table 2 | Relevance of the six SDG transformations for global kidney health

SDG transformation SDGs How SDGs may impact kidney health and well-being

Education, gender and Quality education (SDG 4) inequality

Gender equality (SDG 5)

Reduced inequalities (SDG 10)

Health, well-being and No poverty (SDG 1) demography

Good health and well-being (SDG 3)

Partnerships for the goals (SDG 17)

Energy,

decarbonization and sustainable industry

Affordable and clean energy (SDG 7)

Industry, innovation and infrastructure (SDG 9)

Responsible consumption and production (SDG 12)

Climate action (SDG 13)

Sustainable food, land, Zero hunger (SDG 2) water and oceans

Clean water and sanitation (SDG 6)

Life below water (SDG 14)

Life on land (SDG 15)

Sustainable cities and communities (SDG 8)

Sustainable cities and communities (SDG 11)

Peace, justice and strong institutions (SDG 16)

Digital revolution for sustainable development

infrastry, innovation and
Decent work and economic growth

Improve health of families; improve health literacy; improve opportunities to build work workforce

Improve maternal and child health; improve access to care for women and children; study male predominance in kidney failure

Reduce structural violence; flatten social gradient; address social determinants of health; improve access to screening, early diagnosis and quality treatment; reduce global inequities in access to KRT; reduce imbalance of research and publications skewed to global north

Improve access to health; improve social circumstances, access to education, good nutrition to reduce incidence of kidney disease; reduce catastrophic health expenditure imposed by kidney disease

Increase access to early diagnosis and care under universal health coverage; improve equitable access to prevention, early diagnosis and all treatment; assure quality care; improve well-being and reduce moral distress among health-care workers where resources are limited; develop guidelines for optimal kidney care in high- and low-resource settings; improve access to supportive and palliative care if dialysis and transplantation are not available to those who need them

Improve international collaboration for capacity building, research advocacy; good governance, transparent priority setting regarding KRT

Improve infrastructure maintenance to permit dialysis, transplantation; improve efficiency of dialysis; reduce corruption and monopolies

Produce dialysis supplies locally; develop new affordable dialysis systems; improve access using mobile technologies; limit industry interference (for example, from the food, beverage, tobacco industry and dialysis industries)

Reduce dialysis waste; increase widespread safe dialyzer reuse to reduce costs and/or waste

'Green dialysis'; support transplantation, which is more environmentally friendly; reduce emissions by supporting local production of dialysis supplies

Improve fetal and childhood nutrition; reduce obesity

Improve WASH to prevent diarrhoea-associated AKI and other infections; reduce water consumption through re-use of dialysis water

Protect marine life to ensure safe and sustained fish consumption (loss of fish as protein source will increase obesity and increase the risk of CKD)

Reduce deforestation to protect agriculture and employment; forests may be a source of new medicines (traditional)

Reduce poverty, improve health through employment; create jobs in the health sector; stimulate local economies through local production of dialysis supplies; reduce unemployment among dialysis and transplant recipients

Reduce risk of non-communicable diseases in healthy cities; improve access to dialysis through affordable and reliable public transport

Improve equity through priority setting and transparent policy making; improve accountability through oversight of policy implementation to determine impact on patients with kidney disease; reduce organ trafficking

Task shifting, patient education, health-care delivery, research supported through task shifting; improve access to care through telenephrology

Partnerships for the goals (SDG 17)

Improve partnerships with communities, health system industry, pharma, public and private sectors to provide maximal equitable and affordable access to kidney care

AKI, acute kidney injury; CKD, chronic kidney disease; KRT, kidney replacement therapy; SDG, Sustainable Development Goal; WASH, water quality, sanitation and handwashing.

Global inequities. Many countries have yet to take practical steps towards reducing inequality within and among countries (SDG 10) ${ }^{19}$, which translates into inequitable access to electricity, safe water and sanitation, public transport, internet, and other amenities and services that facilitate life in modern society ${ }^{2}$. The stark inequities in outcomes and vulnerabilities observed in many countries during the COVID-19 pandemic, and the structural violence impelling the Black Lives Matter movement have forced a global reckoning about how
Black populations especially, but also Indigenous and other 'minority' populations, have been consistently subjected to racism, oppression and colonialism, which have systematically limited their capabilities and negatively affected their health ${ }^{63}$ (BOX 2). Such structural inequities lead to poverty, unemployment, limited education and high mortality ${ }^{25}$. The burden of CKD is greater among minority ethnic groups and disadvantaged communities in all countries ${ }^{30,64,65}$. The association between socioeconomic status and CKD is in part mediated by high-risk 
health-related behaviours, increased prevalence of comorbidities and reduced access to health care, which are often entrenched owing to racism and discrimination experienced throughout the life course ${ }^{66}$.

Country-level capacity for kidney care varies greatly around the world ${ }^{67,68}$. Between 2013 and 2018, 40\% and $55 \%$ of countries had fewer than 10 doctors and 40 nurses per 10,000 persons, respectively ${ }^{2}$. Several regions still lack access to basic diagnostics, universal access to primary health care and sustainable technologies for the provision of KRT, especially across LICs (FIG. 2). Limited services for the diagnosis, management and monitoring of CKD at the primary health care level are especially evident in LICs in Africa, where only $12 \%$ of the population has routine access to diagnostic tests for kidney disease, including routine blood and urine tests $^{67}$ (FIG.2).

In 2017, a global survey reported that haemodialysis was available in over $90 \%$ of countries ${ }^{68}$. However, access to and distribution of KRT across nations remains highly inequitable and is often dependent on out-of-pocket expenditure and access to private facilities in LICs. Chronic peritoneal dialysis was available in over $90 \%$ of upper-middle-income countries and HICs, in contrast to $64 \%$ of LMICs and $35 \%$ of $\mathrm{LICs}^{68}$. Acute peritoneal dialysis had the lowest availability globally. Over $90 \%$ of upper-middle-income countries and HICs offered kidney transplantation, with over $85 \%$ of these countries reporting both living and deceased donor programmes.
LICs had the lowest availability of kidney transplantation $(12 \%)$, which was predominantly living donor transplantation ${ }^{68}$. Inequalities in individual access to the spectrum of kidney care persist and are often associated with ethnicity, socioeconomic status and geography in HICs, and weak health systems, inadequate infrastructure, geography and reliance on out-of-pocket payments in $\mathrm{LICs}^{30,69}$.

\section{Health, well-being and demography}

This transformation (SGDs 1-5, 8, 10) falls largely under the ministry of health but requires reliable data collection and reporting. Kidney health should be positively impacted through health promotion, identification of risk factors and disease burdens, achievement of universal health coverage (UHC) and delivery of quality health care.

Poverty. Poverty (SDG 1) impacts how and where individuals live, their food choices, access to education, employment opportunities, access to technology and innovations, and their knowledge and exercise of their rights $^{70}$. The proportion of people living in extreme poverty (that is, living on $<$ US $\$ 1.90$ a day) declined from $36 \%$ in 1990 to $8.6 \%$ in 2018; however, the rate of decline has slowed $^{2}$. Importantly, $8 \%$ of employed people live below the poverty line, which reflects unjust working conditions. More women than men live in poverty, and poverty rates are higher in rural and conflict-affected areas.

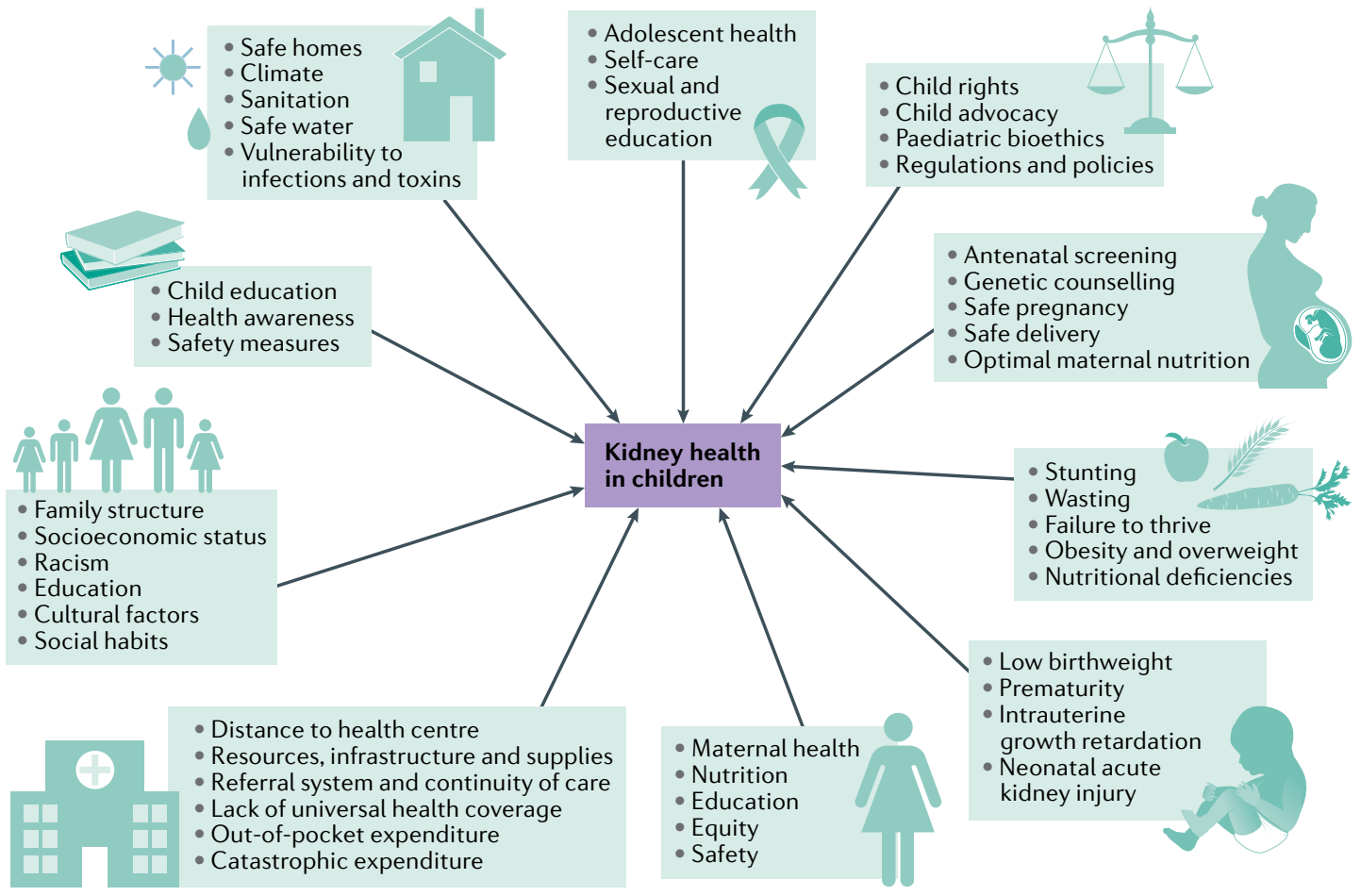

Fig. 1 | Multiple structural factors influence kidney health in children. Conditions experienced during fetal life and early childhood affect the physical and psychosocial development of children. The effects of these conditions persist throughout the life course and influence an individual's future health and that of their children. Achievement of the Sustainable Development Goals (SDGs) is urgent to enable each child to maximize their own capabilities and to improve the health of future generations. Poverty has an overarching impact on child health and well-being. Children require a safe home and school environment, access to healthy food, good education, freedom from forced labour and access to recreational time and space to thrive and grow up healthy. Moreover, healthy and educated mothers have healthier children. 
a Primary care level

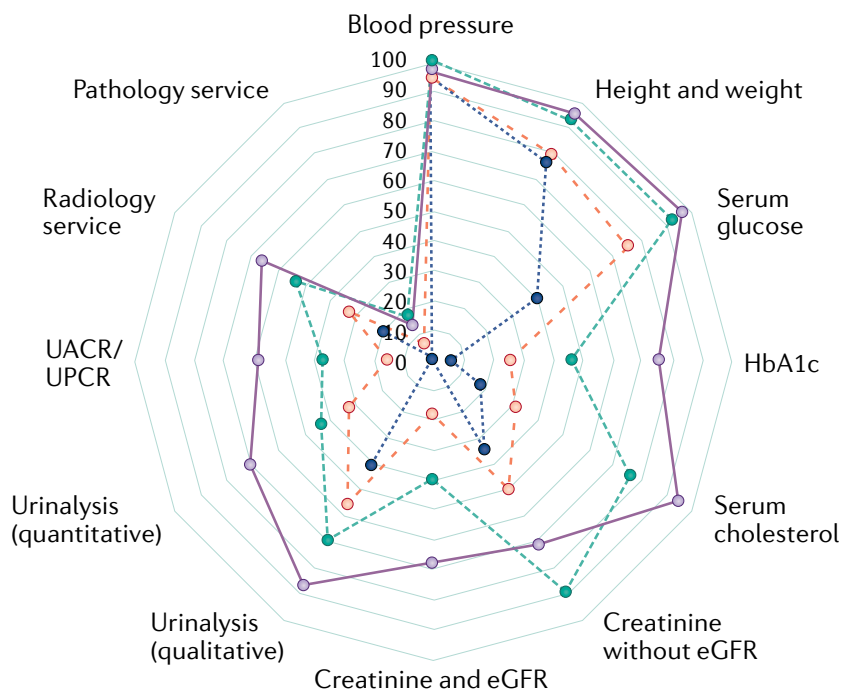

b Secondary or tertiary care level

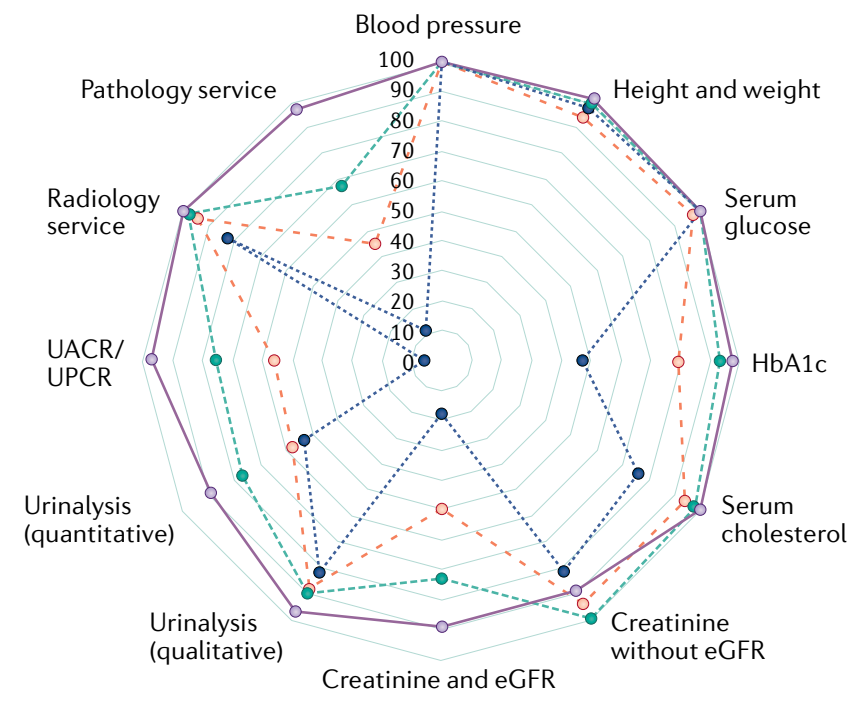

-... Low income

- - - Low-middle income

Upper-middle income

- High income

Fig. 2 | Availability of resources to detect kidney disease at primary, secondary or tertiary care levels across country income categories. Spider diagrams illustrating the relative availability of services required to screen for and detect kidney disease at primary (a) and secondary or tertiary (b) care levels. Each concentric dodecagon reflects the proportion of countries within a specific income bracket (line colour) in which the given screening and/or diagnostic tool was available, beginning with $0 \%$ in the centre and $100 \%$ as the outermost line. Some important resources such as reporting of the estimated glomerular filtration rate (eGFR) and quantification of urinary protein were absent in low-income countries, which demonstrates marked global inequities in access to basic quality screening for kidney disease. UACR, urinary albumin-to-creatinine ratio; UPCR, urinary protein-to-creatinine ratio; $\mathrm{HbA}_{1 c}$, glycated haemoglobin. Adapted from REF. ${ }^{185}$, Elsevier.

Globally, $55 \%$ of people have no access to social protection, with wide disparities between HICs and LICs (14\% in Europe versus $87 \%$ in sub-Saharan Africa $)^{2}$.

Poverty impacts three major determinants of health - access to health care, environmental exposures and health behaviour - all of which contribute to health disparities ${ }^{41}$. Major contributors to disparities in selfassessed health include inequities in social protection, employment, knowledge, education, housing and infrastructure ${ }^{71}$. Of note, all of these factors are being negatively impacted by job losses and lockdowns during the COVID-19 pandemic, which will have long-term consequences for health and well-being.

Out-of-pocket costs associated with seeking health care present major barriers to care and contribute to late presentation and increased mortality ${ }^{72}$. Among 8.9 million persons with CKD from ten countries, lack of health insurance or home ownership were associated with poor health outcomes ${ }^{57}$. Individuals with chronic diseases are especially vulnerable to catastrophic health expenditure because of ongoing costs and the inability to work ${ }^{65,73}$. Among 2,914 individuals from 14 countries (11 HICs, three MICs), the odds of catastrophic health expenditure increased with increasing stage of CKD, and were $78 \%$ higher for patients on dialysis compared with those with moderate $\mathrm{CKD}^{74}$. Transplantation reduced catastrophic health expenditure by half compared with dialysis.

An estimated 100 million people per year are impoverished because of health-care costs ${ }^{51}$. Families with limited financial resources must make tough choices and often reduce food consumption, limit education or sell assets to meet medical debts; even a single episode of diarrhoea might lead to unaffordable health expenses $^{75,76}$. One WHO target is for 1 billion more people to gain UHC by 2023 (SDG 3); currently, the UHC service coverage index (range $0-100$ ) varies from 40 in LICs to 80 in $\mathrm{HICs}^{51}$. Although this WHO target is a laudable aspiration, UHC is fraught with logistical and equity challenges, and should not only ensure access to health care but also ensure that health outcomes improve $^{77}$. Otherwise, UHC might exacerbate inequities if availability does not equate to access and if the quality of care is poor ${ }^{78}$.

Quality health care. An analysis of amenable deaths in 137 countries revealed that 15.6 million excess deaths occurred in LMICs in $2016\left(\right.$ REF $\left.^{79}\right)$. Of these, 7 million could have been prevented through public health interventions. Of the remaining 8.6 million, 3.6 million were attributed to non-use of health-care services but, crucially, 5 million were attributed to poor-quality care ${ }^{79}$. In these cases, precious family resources were spent to no avail. The concept of 'effective coverage' has been proposed as a proxy for quality and a means of estimating the proportion of people in need of an intervention who actually achieve the desired health outcome ${ }^{80}$. The infrastructure necessary to monitor progress towards the SDGs should enable regular tracking of such data to 
inform improvements in coverage and quality. Ironically, many resources in HICs are consumed by profit-driven interventions that do not improve health status. Tracking such over-treatment should also be incorporated into quality metrics.

Quality of care for kidney health requires well-trained primary health-care workers who are aware of kidney disease risk. They must provide safe, reliable and acceptable patient-centred services, and must be able to identify patients who require timely referral for management or planning of KRT. At secondary and tertiary levels, health-care workers should be equipped with infrastructure to provide care for patients with kidney disease, including biopsies, medications, KRT and supportive care. An important component of quality care is quality assurance, which requires monitoring and evaluation of all aspects of service delivery. For example, treating patients with kidney failure with twice-weekly instead of thrice-weekly haemodialysist has been proposed as a means of providing dialysis to more people, but the clinical outcomes of patients must be monitored to ensure safety ${ }^{69,81}$. Similarly, disease registries might permit identification of at-risk populations and hot spots of kidney disease, as well as guide targeted interventions and enable monitoring of their impact ${ }^{82}$.

Systematic screening of high-risk individuals could lead to early disease detection and permit intervention with cheap therapies to manage risk factors and slow the progression of $\mathrm{CKD}^{83,84}$. Given the synergies between the management of CKD and that of hypertension, diabetes and CVD, integrated programmes for NCD control at primary care level would offer substantial benefit. Integration of awareness and screening for $\mathrm{AKI}$ and $\mathrm{CKD}$ in patients with infectious disease (for example, malaria, HIV, tuberculosis, diarrhoea, pneumonia, sepsis or hepatitis) or within maternal health programmes (to address, for example, pre-eclampsia, post-partum haemorrhage, low birthweight or preterm birth) would also reduce the burden of kidney disease. Importantly, expensive, technically demanding interventions such as KRT pose a considerable challenge to UHC. KRT requires disproportionately high expenditure for the benefit of a relatively small proportion of the population and prevention must therefore be prioritized, although the needs of patients who already have kidney disease cannot be overlooked ${ }^{27,85,86}$.

\section{Energy, decarbonization and industry}

This transformation (SDGs 1-16) requires engagement between industry and ministries of environment, labour, transport, energy and commerce. Sustainable investments in infrastructure and industry are required to increase energy efficiency and reduce pollution. This transformation will indirectly improve kidney health by ensuring a healthier environment, safer places to live and work, and a healthier planet. Kidney care might also be directly impacted through innovations to develop greener KRT.

Air pollution. Energy production is a major contributor to climate change and generates $60 \%$ of greenhouse gases $^{25}$. Households and the food sector consume $29 \%$ and $30 \%$ of global energy, and generate $21 \%$ and $22 \%$ of carbon dioxide emissions, respectively ${ }^{25}$. SDG7 focuses on access to affordable and clean energy. International financing to encourage the development of renewable energy in LICs almost tripled between 2009 and 2019; by contrast, investments in HICs increased by $38 \%{ }^{87}$. Energy efficiency is also increasing ${ }^{25}$. The proportion of people with access to electricity has increased from $78 \%$ in 2000 to $89 \%$ in 2017 ; however, 840 million people still have no access to electricity ${ }^{25}$. Access to electricity reduces the use of biofuels for cooking and exposure to household air pollution as a risk factor for CKD and other NCDs.

Current data suggest that $17-20 \%$ of the global CKD burden might be attributable, in part, to air pollution $^{88}$, which includes both ambient and indoor air pollution (SDG 11). Ambient fine particulate matter air pollution $\left(\mathrm{PM}_{2.5}\right)$ is associated with increased risk of and progression of $\mathrm{CKD}^{89,90}$. Other pollutants, including ambient coarse particulate matter, nitrogen dioxide and carbon monoxide are also associated with risk of CKD and kidney failure ${ }^{91}$.

ASM associated with household and ambient air pollution ranges from 17.8 in HICs to 131.7 in LICs and $\mathrm{LMICs}^{51}$. In $2017,47 \%$ of the global population was exposed to household air pollution from the use of solid fuels (such as coal, wood, charcoal and dung) for cooking ${ }^{92}$ and $60 \%$ of deaths attributed to indoor pollution occur in women ${ }^{25}$. India has successfully reduced its proportion of households cooking with solid fuels by $16 \%$ by prompting a shift to liquefied petroleum ${ }^{92}$.

Population-weighted exposure to air pollution has increased as urban migration has accelerated. In 2017, $92 \%$ of the world's population lived in areas that exceeded the WHO Air Quality Guideline for healthy air ${ }^{92}$. Multisectoral action is urgently needed to galvanize efforts to reduce exposure to ambient and indoor air pollution $^{93}$. In the USA, following the introduction of the Clean Air Act, $\mathrm{PM}_{2.5}$ levels have fallen dramatically over the past 30 years $^{94}$. Similarly, China set benchmark air quality standards in 2013 and implemented programmes to reduce reliance on coal, curb industrial emissions, limit the number of vehicles in some metropolitan areas and facilitate a transition to lower-emission energy systems, which led to the reduction of annual average $\mathrm{PM}_{2.5}$ concentrations by one-third from 2013-2017 (REFS ${ }^{92,95}$ ). However, many regions still have very high levels of ambient and indoor air pollution, and a 2019 report suggests that levels of pollution currently considered safe might be hazardous ${ }^{92}$. Lockdowns during the COVID-19 pandemic have led to reductions in air pollution, but these improvements are unlikely to be sustained ${ }^{96}$.

Water pollution. Globally, summary exposure values for unsafe water dropped nearly $25 \%$ over the last three decades, although water quality has deteriorated in some countries ${ }^{97}$. Water pollution is responsible for over 1.2 million deaths annually ${ }^{97}$. Over $80 \%$ of waste water from human activity enters rivers or the sea without pollutant removal ${ }^{25}$. Water contamination with pesticides, agricultural products, hydrocarbons, perfluorinated chemicals and heavy metals has been linked to 


\section{Box 3 | Water, sanitation and CKD in Jalisco, Mexico}

Towns along Lake Chapala (Jalisco state, Mexico), especially Poncitlan, have a high prevalence of chronic kidney disease of unknown aetiology (CKDu). Kidney disease is more prevalent in adults from these communities than in those from other Jalisco municipalities - CKD, $20.1 \%$ versus $10.4 \%$; proteinuria, $36.1 \%$ versus $11.0 \%$. Similar findings were reported for children ${ }^{194,195}$. Unsafe drinking water, poor sanitation and contamination of the lake and water wells are likely risk factors.

Lake Chapala is contaminated by pesticides, as well as industrial and household waste, because only 2 of 19 wastewater treatment plants located in the sub-basin of the lake are functional and their capacity is limited to treating organic matter ${ }^{196,197}$. High mercury concentrations are present in fish from the lake and fish consumption is associated with high hair mercury concentrations in young women ${ }^{198}$. Such contaminants likely contribute to $\mathrm{CKDu}^{19}$. Pesticides are also widely used without protection and over $70 \%$ of children have tested positive for glyphosate in the urine ${ }^{200}$. A synergy between heavy metals and glyphosate might result in kidney damage ${ }^{201}$. Additionally, the residues deposited in the soil might eventually contaminate water wells for human use ${ }^{200-202}$.

Many households lack proper sanitation and tap water. Moreover, water wells are contaminated by springs containing high levels of arsenic and coliforms ${ }^{203}$. The incidence of waterborne disease and gastroenteritis is high in children and these illnesses are associated with a high mortality rate ${ }^{204}$. Associated recurrent episodes of AKI might also contribute to CKDu in this population.

Although measures have been approved by Jalisco's Human Rights Commission and by the Inter-American Commission on Human Rights ${ }^{197,205}$, no action has been taken to address the contamination of Lake Chapala or to provide safe drinking water and adequate sanitation to these communities, which might prevent CKD. The State response has been limited to the implementation of a CKD screening programme, the setting up of a CKD registry and the provision of nephrology care ${ }^{206}$.

various kidney diseases ${ }^{98,99}$ and key relationships exist between water quality, sanitation and CKD (BOX 3). Exposure to water contaminated with heavy metals (such as cadmium, lead, mercury or arsenic) leads to acute tubulo-interstitial disease and CKD. Exposure to water contaminated with agricultural chemicals (such as paraquat, glyphosate and organochlorines) also leads to tubular and glomerular injuries, which result in CKD and kidney failure ${ }^{100-102}$.

Climate change. Climate change will be the most consequential health challenge of the twenty-first century (SDG 13). Climate change impacts health in numerous ways - leads to the emergence of new infectious pathogens with devastating consequences, increases infection risks and leads to a rise in snakebites - and many of these changes have important consequences for kidney health ${ }^{103,104}$. Also, humans might adapt to a warming climate by increasing fat mass, which provides metabolic water as a putative protective mechanism against water shortage. Such adaptations might contribute to the obesity and diabetes epidemics ${ }^{103}$. Recurring exposures to heat stress might also contribute to the epidemics of CKD of unknown aetiology in Latin America and South Asia ${ }^{105}$. Working in high ambient temperatures without appropriate access to drinking water or breaks to empty the bladder can also damage the kidney ${ }^{106}$.

In addition, climate change results in extreme weather events, which can provoke displacement and threaten food security. These effects afflict most profoundly individuals affected by illness and poverty, among whom people with kidney disease are highly vulnerable ${ }^{107}$. By 2019, the Paris Climate Agreement had been ratified by 185 parties, offering hope that global collaboration at national levels will bring progress ${ }^{2}$.
Sustainable industry. Countries and large companies are progressively adopting policies for sustainable consumption and production (SDG 12) ${ }^{25}$. Delivering high-quality KRT requires extensive supply chains, logistics, technical expertise and, in the case of haemodialysis, water purification systems. Green nephrology initiatives are emerging in response to the need for innovation to improve the sustainability of KRT delivery - developing dialysis systems that are more energy-efficient and water-efficient could reduce energy and water consumption, and dialysis waste ${ }^{108,109}$. Dialyzer re-use is frequent in low-income settings; this approach reduces costs and waste but requires knowledge and infrastructure to ensure safety ${ }^{110}$. Wearable kidneys and artificial kidneys are also being developed and tested, which may dramatically reduce waste and improve well-being ${ }^{111}$. Kidney transplantation is the treatment for kidney failure that produces the least waste.

\section{Sustainable food, land, water and oceans}

Ministries of agriculture, forestry, natural resources and the environment will be key to achieving this transformation (SDGs 1-3, 5, 6, 8, 10-15). Healthier land and water environments will increase the sustainability of food, improve access to land for agriculture and shelter, and reduce encroachment on animal habitats, which can lead to new diseases. Kidney health should be directly positively impacted through improved maternal and child nutrition, and access to healthy and affordable food throughout the life course. Healthier forests and oceans will positively impact climate change.

Nutrition. Good nutrition (SDG 2) is highly relevant to meeting 12 of the SDGs and sustainable food production is central to ending world hunger. Globally, one third of children younger than 5 years have stunted growth, low weight for height (that is, wasting) or overweight, and half have hidden hunger ${ }^{112}$. Factors contributing to the burden of wasting and stunting include later birth order, male gender, maternal illiteracy, maternal short stature, poor sanitation and water supply ${ }^{113-115}$. Undernutrition and stunting also contribute to reduced performance at school and loss of economic productivity. Nutrition interventions to reduce childhood stunting (for example, supplementation or education) yield significant benefit in terms of increased future wages for men and women, and are highly cost-effective ${ }^{115}$. The global obesity pandemic is juxtaposed with the global burden of malnutrition and food insecurity. Worldwide, more than 2 billion people have overweight or obesity ${ }^{116}$. One in five children have overweight, up from one in ten two decades ago $^{112}$. One report found positive associations between rises in BMI and increasing annual gross domestic product (GDP) per capita, empowerment of women and urbanization $^{117}$. The COVID-19 pandemic will likely contribute to worsening of both malnutrition and obesity, especially in children, owing to lockdowns and increasing poverty ${ }^{26}$.

Nutrition has a major impact on kidney disease. Undernutrition contributes to poor pregnancy outcomes, low birthweight and child stunting, and increases the risk of infections such as those that cause diarrhoea 
and tuberculosis ${ }^{54,112}$. Food insecurity is associated with an increased risk of CKD in adults, especially those in low socioeconomic groups, which reflects lack of access to the quality food necessary to reduce risks of hypertension and diabetes ${ }^{118}$. Overweight and obesity increase risks of the hypertension, diabetes, kidney stones and inflammation, and are also important risk factors for $\mathrm{CKD}^{119}$.

Tackling nutrition requires a broad approach to ensure that people have access to healthy and adequate food choices. This approach requires not only employment and economic growth, but also public health oversight of food composition and advertising, knowledge about healthy food, easily obtainable healthy food and healthy cities that promote safe physical activity ${ }^{84}$. Population-level reductions in salt (for example, in the $\mathrm{UK}^{120}$ ), sugar (for example, in Mexico ${ }^{121}$ ) and trans-fat intake (for example, in Costa Rica and New York City ${ }^{122}$ ) have been successfully achieved in various societies. These changes have been associated with reductions in blood pressure and cardiovascular disease, and are projected to reduce rates of obesity and incident diabetes; they are also likely to reduce the burden of kidney disease ${ }^{121-123}$. An analysis of the impact that a policy aimed at lowering salt consumption to $5 \mathrm{~g}$ per day had on hypertension in South Africa revealed that it was a cost-effective intervention that had a significant effect in reducing deaths due to cardiovascular disease and kidney failure ${ }^{124}$. Importantly, the policy also significantly reduced catastrophic health expenditure, especially among the poorer quintiles ${ }^{124}$.

Safe water. Access to safe drinking water (SDG 6) and safe sanitation has increased since 2000 (REF. ${ }^{2}$ ). However, in 2017, three of ten people remained without access to safe drinking water, six of ten without access to safe sanitation and two of five without basic handwashing facilities ${ }^{125}$. One in four health centres lacked access to essential water services ${ }^{25}$. Globally, in $2016,69 \%$ of schools had basic drinking water, $66 \%$ had basic sanitation facilities and $53 \%$ had basic handwashing facilities ${ }^{126}$. All of these statistics are especially concerning in 2020 in light of the COVID-19 pandemic, where hand hygiene is crucial to curbing transmission. Some countries have made considerable progress - in India, for example, almost all schools now have some facility for sanitation compared with $50 \%$ in 2000 (REF. ${ }^{126}$ ) - but major inequalities remain ${ }^{125}$. In 2017 , in 51 of 82 countries, handwashing facilities with soap and water were twice as frequent among the wealthiest as among the poorest quintiles, although coverage gaps were narrowing between rural and urban areas ${ }^{125}$. In 2016, crude death rates due to unsafe water, sanitation and hygiene in LICs were twice as high as in LMICs, and 145 times as high as in $\mathrm{HICs}^{51}$. Almost 1,000 children die daily from preventable diarrhoeal diseases; an unknown proportion of these deaths might be due to $\mathrm{AKI}^{25}$. Diarrhoea is an important contributor to malnutrition and is also a major cause of catastrophic health expenditure $\mathrm{e}^{75,112}$. Improved water and sanitation policies can thus positively impact child health by reducing poverty, disease and stunting, and by improving educational opportunities and gender equity ${ }^{127}$. Poverty-related factors such as infectious diseases secondary to poor sanitation, unsafe drinking water, environmental pollutants and high concentrations of disease-transmitting vectors, are all drivers of CKD in $\mathrm{LICs}^{128}$ (BOX 3).

Environment. Conservation and sustainable use of the world's marine resources, sustainable management of forests and land, desertification mitigation strategies and preservation of biodiversity (SDGs 14, 15) relate to kidney health both directly and indirectly. For example, depletion of marine resources might accelerate the obesity epidemic as many coastal communities rely on marine resources as the primary source of caloric and protein supply. Jeopardizing this resource might force a transition to less nutritious and obesogenic food sources $^{129}$.

\section{Sustainable cities and communities}

This transformation (SDGs 1-16) requires collaboration across multiple ministries, especially transport, urban planning, water and the environment. Kidney health will be positively impacted in people living and working under safe, less crowded and less stressful conditions, in walkable cities, with green recreational areas, good public transport, good local governance and freedom from discrimination.

Employment. Employment and decent work conditions are essential for good health and sustainable communities (SDG 8). Economic growth is both essential for and a consequence of labour and human activity. Labour productivity (real GDP per capita) has increased by $2.1 \%$ from 2017 to 2018 (REF. ${ }^{25}$ ). Global unemployment has declined from $6.4 \%$ in 2000 to $5.7 \%$ in 2017 , although $\sim 8 \%$ of workers live in poverty and $61 \%$ work in the informal sector, where they have little social protection or control over employment conditions ${ }^{25}$. In 2018, one in five global youth (15-24 years of age; $30 \%$ of women and $13 \%$ of men) were not working, studying or training ${ }^{2}$. Importantly, the COVID-19 pandemic has not only increased unemployment but also highlighted the vulnerability of individuals with low-paying jobs, many of whom perform jobs essential to society. These individuals, who are often women and from minority ethnic groups, cannot afford to remain locked down and are therefore at increased risk of exposure to infection ${ }^{130}$. Further inequities are evidenced by the global gender pay gap - pay remains $12 \%$ higher for men and this gap rises to $20 \%$ in professional occupations ${ }^{25}$. In LMICs, $\mathrm{AKI}$ and CKD disproportionately affect young, economically productive people. Premature mortality from lack of access to KRT can therefore also reduce the labour force and drive household poverty; kidney disease prevention would mitigate this impact ${ }^{6,131}$.

Sustainability and innovation. The real GDP growth rate in LMICs had increased from $4.8 \%$ in 2017 to $5.7 \%$ in early 2020 , but remains below the $7 \%$ projected in the 2030 Agenda and will be further hampered by the economic consequences of the COVID-19 pandemic $^{132}$. Over $80 \%$ of the world's population live in LICs and 
LMICs but these countries account for only $20 \%$ of global health spending ${ }^{133}$. Importantly, health spending does not necessarily equate with quality health care. To attain the SDGs, $75 \%$ of health investment should be allocated to the health system - including employment of health-care workers, and building and operating clinics, hospitals and laboratories - and 25\% to prevention or treatment of specific diseases, or outreach to vulnerable communities ${ }^{134}$. Primary prevention of NCDs through implementation of the WHO's Best Buys - reducing consumption of tobacco, alcohol and unhealthy diets, increasing physical activity, managing CVD and diabetes, and preventing and managing cancer - is highly cost-effective ${ }^{135}$. Investments in the prevention of infectious diseases through vaccinations, safe water, and maternal and child health services are also cost-effective ${ }^{133}$.

All of these interventions promise to reduce the future burden of kidney disease by improving general health. More inclusive, safe, resilient and sustainable cities provide the conditions for healthier lives and help to curb the epidemics of obesity and diabetes, which are major drivers of CKD globally ${ }^{136}$. However, as UHC expands to cover more diseases, budget allocation for prevention tends to get eroded ${ }^{137}$, which is a concerning trend. Of note, major industries (for example, the tobacco and food industries) often interfere with prevention efforts, whereas others (for example, pharma, health insurance and hospitals) profit from the management of preventable diseases and their influence might distort health-care priorities ${ }^{138}$.

Globally, the prevalence of KRT is proportional to GDP per capita up to $\sim$ US $\$ 14,000$, after which it plateaus, suggesting that, in countries with a GDP per capita above US\$14,000, access to dialysis is more equitable and less dependent on the patient's ability to pay or restricted service provision ${ }^{139}$. Some countries with lower GDPs per capita, such as Thailand (2018 GDP per capita US\$7,273) and Colombia (2019 GDP per capita US\$6,498), have implemented deliberate policies to include dialysis under $\mathrm{UHC}^{140}$. Following the inclusion of KRT under UHC in these countries, health expenditure per capita rose, but poverty rates and catastrophic health expenditure declined significantly ${ }^{140,141}$. 'Peritoneal dialysis first' programmes, as implemented in Thailand, might permit the most appropriate use of precious resources to provide affordable quality and sustainable chronic dialysis for those in need, if costs can be contained ${ }^{142}$. In Colombia, since the creation of the "Cuenta de Alto Costo" (that is, high-cost account) to pool funds, thereby redistributing financial risk for catastrophic conditions across the entire population ${ }^{143}$, the prevalence of treated kidney failure has increased but the incidence has decreased, suggesting the success of integrated prevention strategies and the utility of a CKD registry to monitor outcomes ${ }^{144}$. However, this system has been criticized for lack of transparency, emphasis on KRT rather than prevention, and persistent inequalities regarding the financial protection of households ${ }^{145,146}$.

In many MICs and LICs, however, the opportunity costs of providing dialysis are considered too great. As an example, South Africa (2018 GDP per capita US\$ 6,374) has elected to ration dialysis in the public sector ${ }^{147}-$ only patients who are eligible for kidney transplantation are covered for dialysis therapies. This policy not only highlights many ethical issues in the provision of KRT but also elucidates the sharp divisions between public and private sectors of health care in sub-Saharan Africa, where access to KRT in the private sector is only restricted by an individual's ability to pay ${ }^{148}$ (Supplementary Table 3). Similarly, in Kenya, increasing awareness of the local burden of kidney disease led to a government-initiated policy to increase access to haemodialysis and improve nephrology care ${ }^{149}$. However, budget constraints make sustainable universal access to dialysis nearly impossible unless major innovations can bring down costs. Additionally, LMICs must be mindful of the increasing gap between patients with kidney failure who receive chronic dialysis and those who receive kidney transplants. Failure to simultaneously expand access to transplantation for those who are eligible not only precludes them from optimal therapies but also restricts access to dialysis for new patients when slots are limited, and increases the overall costs of KRT. Kidney transplantation remains the most cost-effective treatment ${ }^{74}$.

Aiming for sustainable KRT offers challenges and opportunities for innovation ${ }^{150}$. Strategic partnerships between governments, the private sector, philanthropic and non-governmental organizations ${ }^{151}$, professional societies and capital investment partners remain underutilized. Civil rights and community advocacy groups remain scarce. The cost of equipment and consumables required for chronic haemodialysis and peritoneal dialysis remains prohibitively expensive and unchallenged, despite profits in the dialysis industry being high. The economic impact of creating local hubs for the management of CKD using locally produced materials remains underexplored. Such activity could create opportunities for local employment and grow local economies, while retaining skilled individuals. Ideally, production of disposables and materials should be local, such that micro-economic revenue returns to the community, while reducing transportation costs and environmental impact.

A key indicator for innovation is research capacity. The global investment in research and development has increased from US $\$ 739$ billion in 2000 to US $\$ 2$ trillion in 2016, although this rise has occurred disproportionately in Europe, North America and China ${ }^{25}$. Historically, however, kidney disease has tended to be underfunded in proportion to the disease burden ${ }^{152}$. The number of researchers per million population has risen globally from 804 in 2000 to 1,163 in 2016 , but the rise is unevenly distributed, with only 91 researchers per million in sub-Saharan Africa ${ }^{2}$. Ironically, sub-Saharan Africa is predicted to have one of the highest rates of kidney disease, although epidemiological data are lacking. Training programmes and regional centres of excellence are being established, but much of the research enterprise remains in the hands of researchers from HICs ${ }^{67,153,154}$.

Despite impressive local efforts, such as the World Kidney Day campaigns, to disseminate information 
about CKD and AKI, only $10 \%$ of patients with CKD are aware of their disease, and awareness of AKI and its implications among clinicians is low ${ }^{40,155}$. Innovative epidemiological surveillance systems that can be integrated into clinical care models are urgently needed to address several key areas - developing and promoting guidelines for kidney disease screening in routine primary care; targeting resource allocation; recognizing upstream risk factors for kidney disease; and fostering local and global collaborations through networks of primary care providers, nephrologists, public health experts and policy-makers. As kidney health is impacted by all SDGs, integration into an SDG dashboard might provide insights regarding progress in addressing structural risk factors (TABLE 1); poor performance on several goals increases the risk of CKD.

Innovation also includes implementation of policies such as sodium restriction in food, tax-based incentives encouraging healthy lifestyle choices, task-sharing within the health-care workforce and the use of information technology for education and treatment at the population level. Other novel interventions such as screening and educating men about hypertension in barber shops, using fixed-dose polypills to simplify treatment regimens, tailoring therapy to a person's genotype, or generating donor chains for kidney transplantation are encouraging ${ }^{10,131,156-159}$. Rollout and scaleup of such innovations should be preceded by robust implementation research to understand the potential contextual factors that might impact the success or failure, as well as the harms or benefits, of the interventions ${ }^{160}$.

Stability. Stable and sustainable societies are required for human beings to flourish (BOX 1) and for protection of the environment (SDG 16). Stable institutions are required to develop and implement policies towards achieving the SDGs, and to be accountable for successes, failures and course corrections. Good governance and multisectoral collaboration is especially needed for NCDs, which demand complex attention to many social and structural determinants of health, integration of public and private health systems, and sustainable approaches to financing ${ }^{21,161}$. Venezuela, for example, implemented progressive policies in the early 2000 s to reduce inequities - free health care, for example, was a right guaranteed by the Constitution. Subsequently, corrupt governance has led to a growing humanitarian crisis, with a considerable impact on the health system and dire consequences for patients with kidney disease (BOX 4).

Globally, rates of homicide, violence against women and children, human trafficking and killing of human rights defenders are all increasing ${ }^{2}$. Violence against health-care workers is also increasing ${ }^{162}$. These factors all impact the health and well-being of individuals and society in general ${ }^{163}$. On a larger scale, armed conflicts negatively impact many if not all SDGs, including civilian health ${ }^{164}$ (BOX 4). The excess morbidity and mortality of civilians in wars is more likely to be indirect through the deterioration of support systems needed to prevent and treat infections and NCDs, and forced migration, rather than a direct result of combat ${ }^{165}$. Conflict also has indirect impacts on health through exacerbation of poverty, food and water insecurity, gender inequities, loss of employment, lack of formal housing and lack of social protection.

Traditional wars between two states have been replaced by conflicts between states and rebel groups, non-state parties and one-sided violence by armed entities against civilians. These actions extend the duration of conflicts, increase civilian suffering, and worsen inequalities and violation of basic human rights ${ }^{166}$. Armed conflict has been associated with higher rates of CVD, diabetes, hypertension, and alcohol and tobacco use in civilians $^{167}$, as well as CKD in injured soldiers ${ }^{168}$. AKI due to crush injury and sepsis is common, and toxic AKI from unusual causes such as mushroom or thallium intoxication have also been reported ${ }^{169,170}$. The impact of armed conflict on the onset and progression of early-stage CKD is less well documented, but the increased prevalence and sub-optimal management of diabetes, hypertension, diarrhoeal diseases and low birthweight, strongly suggest it has a negative effect ${ }^{167}$. Higher prevalence of kidney failure in this setting has not been documented, likely due to low dialysis rates, but the impact of armed conflict on kidney failure care has been reported ${ }^{169,171}$ (BOX 4). The solutions to sustaining KRT in conflict regions must be creative - cross-border delivery of aid can bypass unfriendly governments and militant checkpoints; telenephrology and medical missions provided by expatriate nephrologists can cover shortages in human resources; and aid can be provided by international and diaspora non-governmental organizations, as well as the dialysis industry. However, continued problems with coordination of aid, lack of expertise of donors and local educational needs demand more coordinated action.

Another important consequence of armed conflicts is the forced migration of populations, including patients with kidney disease. These patients and their host societies face many economic, ethical and cultural challenges $^{172}$. The migration pattern of refugees with kidney failure may differ from that of the general population, as it might be influenced by their health status and the KRT policies of the host country. In Europe, refugees are estimated to represent $1.5 \%$ of the dialysis population ${ }^{173}$. Turkey, Lebanon and Jordan, all of which border Syria, receive many refugees on dialysis; other countries resist providing dialysis services to migrants ${ }^{171,174-176}$.

\section{Digital revolution for sustainable development}

Digital technologies should be harnessed to support this transformation (SDGs $1-4,7-13,17$ ) through collaboration between the ministries of science and technology, energy, communication and infrastructure, as well as support for research and good governance. Kidney health might benefit from technologies that expand access to care, enhance health literacy, health promotion and educational opportunities, as well as epidemiological studies and data tracking.

By the end of 2018, over half of the world's population had access to the internet, although many more 


\section{Box 4 | Peace, justice and strong institutions are needed to tackle kidney failure}

Good governance and solidarity on both national and international levels are required to ensure sustainability of access to quality care for patients with kidney failure, who are amongst the most vulnerable in unstable health systems.

\section{Venezuela}

In Venezuela, despite the introduction of universal health coverage in 2003, lack of governance, oversight and accountability have affected the quality of care available to patients with kidney disease. The economic crisis in the country is highlighted by the decline in domestic growth (from $5.6 \%$ in 2012 to $-18 \%$ in 2018), the rise in unemployment (from $7 \%$ in 2015 to $37 \%$ in 2018) and an increase in overall inflation of 5,395,536,286\% between 2013 and $2019\left(\right.$ REF $\left.^{207}\right)$.

A 2018 national hospital survey highlights the precarious state of the Venezuelan health-care system ${ }^{208}$.

- $33 \%$ of 16,238 public hospital beds were non-functional

- $43 \%$ of diagnostic laboratories were not operational

- $67 \%$ of hospitals reported electrical failures

- $70 \%$ of hospitals reported water shortages

- $62 \%$ of hospitals reported violent events by family members

- $88 \%$ decline in medicines

- $79 \%$ decline in medical supplies

No official kidney replacement therapy (KRT) statistics or outcomes have been reported since $2010\left(\mathrm{REFS}^{209-211}\right)$.

- KRT prevalence declined from 510 per million population (pmp) to an estimated 331 ppm in 2019 (35\% decrease) despite KRT being covered under $\mathrm{UHC}^{212}$.

- The peritoneal dialysis programme was discontinued in 2017 , leading to an $85.6 \%$ decline in patients receiving this type of dialysis since 2013.

- In 2019, as many as 574 of 2,476 haemodialysis machines (23\%) were non-functional ${ }^{213}$.

- The deceased donor organ transplantation was discontinued in 2017 and no waiting list has been maintained since then.

- For several years, patients have relied on non-governmental organizations and charitable donations for access to post-transplant medication; these drugs became available again in 2019 through social security, with limitations.

- 30,000 physicians have emigrated, escalating since 2015 (REF. ${ }^{214}$ ).

\section{Syria}

Since the Syrian civil war began in 2011, 5.6 million people have fled the country, 6.6 million people are internally displaced and 2.98 million people are in besieged, hard-to-reach areas ${ }^{215}$.

The ongoing war has had a devastating impact on KRT provision in the country:

- 13 of 44 dialysis facilities have shut down because of destruction or lack of funding.

- In 2011, half of patients receiving dialysis in a hospital-based dialysis unit died because of an army closure of the unit.

- Harassment at checkpoints prevents patients from reaching dialysis units and dialysis supplies are often confiscated.

- In 2015, in rural Damascus, $42 \%$ of patients with kidney failure received dialysis only once a week in besieged areas versus $7 \%$ of patients in non-besieged areas; yearly mortality was $48 \%$ and $21 \%$, respectively.

- In 2020, 7 of 20 dialysis units closed after a government offensive in Northwest Syria (unpublished observations, M.S.).

- Hepatitis $C$ prevalence is 50\% in northwestern Syria, compared with $15 \%$ in other regions of the country.

- Two nephrologists care for 600 patients in 29 clinics in Northwest Syria; dialysis nurses take on the roles of technicians, dieticians, social workers and physicians.

- Number of transplants performed - 385 in 2010, 154 in 2013 and 251 in 2018.

- Number of operational transplant centres - 8 in 2013, 4 in 2013 and 6 in 2018.

- Unconfirmed reports on exploitation of kidney donors have surfaced in the lay media ${ }^{216}$. In many areas, patients struggle to obtain medications from government pharmacies and are dependent on international and expatriate non- governmental organizations (unpublished observations, M.S.).

- In Northwest Syria, post-transplant patient care has been provided by an endocrinologist who is a transplant recipient himself ${ }^{217}$. people have access in HICs than in LICs ${ }^{2}$. Many people (90\%) live within range of a broadband network but $16 \%$ remain without access ${ }^{25}$. The use of mobile technologies and digital interventions has the potential to facilitate task sharing, tailored patient and health-care worker education, patient monitoring and support, research and health systems strengthening ${ }^{177}$. As an example, the rapid dissemination of research findings and clinical experiences via Twitter, webinars and other platforms contributed considerably to the kidney community's approach to managing patents with COVID-19. These exchanges included dissemination of information on the use of acute peritoneal dialysis in the face of shortages of haemodialysis equipment in HICs. However, premature dissemination of information has also created confusion where non-robust or fraudulent data have circulated widely ${ }^{178}$. Digital platforms are also useful for advocacy and engender solidarity and interpersonal support in times of crisis $^{179}$. Dissemination of medical education through online teaching tools can bring knowledge to most corners of the world but caution must be taken to ensure the dissemination and use of appropriate and unbiased content ${ }^{177}$. Similarly, patient education tools hold promise in facilitating quality self-care and remote care but bias from sponsors must be avoided. Improvement in technology also offers better opportunities for disease surveillance and monitoring of policy implementation. Of note, data privacy concerns require careful deliberation $^{180}$.

Precision medicine is also gaining ground but, although it creates opportunities to better understand disease pathogenesis, its contribution to improved health in individuals remains unproven ${ }^{181}$. Moreover, emphasis on high-tech individualized approaches might divert research away from population-level problems. However, precision medicine could also contribute to population health by enabling the identification of high-risk population groups that might benefit from targeted interventions (for example, individuals with sickle cell disease, which is a cause of CKD), although affordability will be a major barrier ${ }^{181}$. Another great concern is that high-tech and precision medicine might substantially add to inequity and lead to erosion of solidarity-based health-care systems, given that few people might have access to highly costly therapies (for example, gene therapy), which would nonetheless drive up costs for all ${ }^{182}$. 


\section{Conclusions}

Linking all SDGs with health makes sense from an individual and societal perspective, especially in the pursuit of justice and reduced inequities. Sober reflection is required by the global leadership to determine how to proceed in the pursuit of the SDGs, and how to ensure that the correct priorities are established and pursued, true development is fostered and that global resilience is strengthened going forward ${ }^{183}$.

The COVID-19 pandemic and the Black Lives Matters movement have focused many minds on the global and structural injustices underlying susceptibility to ill health and poor outcomes. The undeniable impact of structural violence on the outcomes of patients with COVID-19 has highlighted the importance of public health for individual health (BOX 2). Many overlaps exist between the global challenges posed by the COVID-19 pandemic and kidney disease. In low-income regions, nephrology professionals function daily under conditions not dissimilar to those experienced in HICs at the peak of the pandemic. These overlaps have created a window of opportunity in nephrology that could enhance the collective recognition of inequities that are pervasive at baseline, and might bolster activity to progress towards true UHC and quality health-care coverage for patients with kidney disease.

Access to care for kidney disease is a global priority and a communal responsibility. At an individual level, clinicians must remain aware of the impact of upstream factors in the overall disease risk of their patients. The use of a 'polysocial risk score' ${ }^{184}$, which would incorporate not only clinical factors but also socioeconomic, environmental and psychosocial factors might serve to highlight the relevance of each SDG for the life and kidney health of each individual. Equitable access to affordable and quality care, particularly in low-income settings, must be achieved through partnerships, advocacy and activism. Over the long term, prevention, early diagnosis and early treatment for kidney disease should be prioritized to minimize the need for expensive therapies. However, the need for KRT cannot be disregarded. Different policy approaches will therefore be required to tackle the burden of kidney disease upstream and to equitably provide access to KRT downstream. Prevention begins far earlier than screening for hypertension and diabetes. It requires healthy children, born to healthy parents, living healthy active lives, being nourished and educated well, having opportunities to maximize their own capabilities as they develop in safe environments, with fair employment opportunities and on a healthy planet. Each SDG has relevance for kidney health.

Improvement in global kidney health will not happen overnight, but should begin with good governance, where priorities are set transparently, and policies are implemented with quality and equity as overarching principles. Across the health system, financing must be sustainable, health-care workers should be educated and supported to fulfil their duties competently and without undue distress, and appropriate infrastructure, medicines and technologies should be available at each health-care level. The paradigm of monitoring and evaluation inculcated by the SDGs should serve to foster accountability and accelerate progress in terms of system efficiency, effectiveness of coverage of care and financial risk protection.

Innovation is urgently needed to improve equitable access to KRT globally by reducing costs and improving capacity to treat, as well as reducing the individual and environmental burdens of KRT. Urgent action is also required globally to curb climate change as a major determinant of kidney health. Maintaining a healthy planet is not only a moral imperative, but also an act of self-interest and self-preservation that should motivate continued progress and optimize the conditions for meeting all SDGs.

\section{Published online 13 November 2020}

1. World Health Organisation. World conference on social determinants of health. (World Health Organisation, Geneva, 2011).

2. United Nations. Report of the Secretary-General on SDG Progress 2019. Special Edition. (United Nations, New York, 2019)

3. Luyckx, V. A., Tonelli, M. \& Stanifer, J. W. The global burden of kidney disease and the sustainable development goals. Bull. World Health Organ. 96, 414-422D (2018).

This article outlines the potential impact of each SDG on kidney health.

4. Jager, K. J. et al. A single number for advocacy and communication-worldwide more than 850 million individuals have kidney diseases. Kidney Int. 96, 1048-1050 (2019).

5. Goldfarb, D. S. et al. Impending shortages of kidney replacement therapy for COVID-19 patients. Clin. J. Am. Soc. Nephrol. 15, 880-882 (2020).

6. Essue, B. M. et al. in Disease Control Priorities. Improving Health and Reducing Poverty, Vol. 9 (eds Jamison, D. T. et al.) 121-143 (World Bank, 2018)

7. Mehta, R. L. et al. International Society of Nephrology's 0by 25 initiative for acute kidney injury (zero preventable deaths by 2025): a human rights case for nephrology. Lancet 385, 2616-2643 (2015).

This paper reports on the global burden of AKI and suggests sustainable approaches to increase awareness of AKI and reduce its burden.
8. Harris, D. C. H. et al. Increasing access to integrated ESKD care as part of universal health coverage. Kidney Int. 95, S1-S33 (2019).

This article summarizes a comprehensive approach to achieving sustainable care, across the spectrum of care, for patients with kidney failure.

9. Foreman, K. J. et al. Forecasting life expectancy, years of life lost, and all-cause and cause-specific mortality for 250 causes of death: reference and alternative scenarios for 2016-40 for 195 countries and territories. Lancet 392, 2052-2090 (2018).

10. Alleyne, G. et al. Embedding non-communicable diseases in the post-2015 development agenda. Lancet 381, 566-574 (2013).

11. Nishtar, S. et al. Time to deliver: report of the WHO Independent High-Level Commission on NCDs. Lancet 392, 245-252 (2018).

12. United Nations. The Millennium Development Goals Report (United Nations, New York, 2015).

13. GBD 2013 Mortality and Causes of Death Collaborators Global, regional, and national age-sex specific all-cause and cause-specific mortality for 240 causes of death, 1990-2013: a systematic analysis for the Global Burden of Disease Study 2013. Lancet 385, 117-171 (2015).

14. McArthur, J. \& Rasmussen, K. Change of pace: accelerations and advances during the Millennium Development Goal era (Global Economy and Development at Brookings, 2017).

15. Sumner, A. \& Tiwari, M. Global Poverty Reduction to 2015 and Beyond: What Has Been the Impact of the MDGs and What Are the Options for a Post-2015 Global Framework? (Institute of Development Studies, 2010).
16. Mercer, T. et al. Mitigating the burden of diabetes in sub-saharan Africa through an integrated diagonal health systems approach. Diabetes Metab. Syndr. Obes. 12, 2261-2272 (2019).

17. Allen, L. N. Financing national non-communicable disease responses. Glob. Health Action 10, 1326687 (2017).

18. Morton, S., Pencheon, D. \& Squires, N. Sustainable Development Goals (SDGs), and their implementation: a national global framework for health, development and equity needs a systems approach at every level. Br. Med. Bull. 124, 81-90 (2017).

19. Sachs, J., Schmidt-Traub, G., Kroll, C., Lafortune, G. \& Fuller, G. Sustainable Development Report 2019. (2019).

Report on SDGs and progress through SDG transformations.

20. Asma, S. et al. Monitoring the health-related Sustainable Development Goals: lessons learned and recommendations for improved measurement. Lancet 395, 240-246 (2020).

21. Luna, F. \& Luyckx, V. A. Why have non-communicable diseases been left behind? Asian Bioeth. Rev. 12 5-25 (2020).

22. World Health Organization. Rapid Assessment of Service Delivery for NCDs During the COVID-19 Pandemic (WHO, 2020).

23. Liyanage, T. et al. Worldwide access to treatment for end-stage kidney disease: a systematic review. Lancet 385, 1975-1982 (2015).

This paper outlines important gaps and inequities in access to dialysis and care for kidney failure globally. 
24. Muralidharan, A. $\&$ White, S. The need for kidney transplantation in low- and middle-income countries in 2012: an epidemiological perspective. Transplantation 99, 476-481 (2015)

25. United Nations. Sustainable Development Goals https://www.un.org/sustainabledevelopment/ (2020).

26. Shadmi, E. et al. Health equity and COVID-19: global perspectives. Int. J. Equity Health 19, 104 (2020)

27. GBD Chronic Kidney Disease Collaboration. Global, regional, and national burden of chronic kidney disease, 1990-2017: a systematic analysis for the Global Burden of Disease Study 2017. Lancet 395 709-733 (2020)

28. GBD 2017 Causes of Death Collaborators. Global regional, and national age-sex-specific mortality for 282 causes of death in 195 countries and territories, 1980-2017: a systematic analysis for the Global Burden of Disease Study 2017. Lancet 392 1736-1788 (2018)

29. Sherr, L. et al. A new vehicle to accelerate the UN sustainable development goals. Lancet. Glob. Health 8, e637-e638 (2020)

30. Norton, J. M. et al. Social determinants of racia disparities in CKD. J. Am. Soc. Nephrol. 27 2576-2595 (2016)

This article outlines the important impact of the social determinants of health, including structura racism, on CKD care.

31. Taylor, D. M. et al. A systematic review of the prevalence and associations of limited health literacy in CKD. Clin. J. Am. Soc. Nephrol. 12, 1070-1084 (2017).

32. Tapia-Conyer, R., Gallardo-Rincon, H. \& Saucedo-Martinez, R. CASALUD: an innovative health-care system to control and prevent noncommunicable diseases in Mexico. Perspect. Public Health 135, 180-190 (2015).

33. Stanifer, J. W., Von Isenburg, M., Chertow, G. M. \& Anand, S. Chronic kidney disease care models in low- and middle-income countries: a systematic review. BMJ Glob. Health 3, e000728 (2018).

34. Jiamjariyapon, T. et al. Effectiveness of integrated care on delaying progression of stage 3-4 chronic kidney disease in rural communities of Thailand (ESCORT study): a cluster randomized controlled trial. BMC Nephrol. 18, 83 (2017).

35. Long, $\mathrm{H}$. et al. Engaging village health workers in noncommunicable disease (NCD) prevention and control in Vietnam: a qualitative study. Glob. Public Health 15 611-625 (2020)

36. Jafar, T. H. et al. A community-based intervention for managing hypertension in rural South Asia. N. Engl. J. Med. 382, 717-726 (2020).

37. Park, S. et al. Impact of electronic acute kidney injury (AKI) alerts with automated nephrologist consultation on detection and severity of AKI: a quality improvement study. Am. J. Kidney Dis. 71, 9-19 (2018)

38. Bullock, B., Donovan, P., Mitchell, C., Whitty, J. A $\&$ Coombes, I. The impact of a pharmacist on posttake ward round prescribing and medication appropriateness. Int. J. Clin. Pharm. 41, 65-73 (2019)

39. Luong, D. T. A. et al. Extracting deep phenotypes for chronic kidney disease using electronic health records EGEMS 5, 9 (2017)

40. Liu, K. D et al. AKI!Now initiative: recommendations for awareness, recognition, and management of AKI. Clin. J. Am. Soc. Nephrol. (2020).

41. WHO Commission on Macroeconomics and Health \& World Health Organization. Macroeconomics and health: investing in health for economic development: executive summary/report of the Commission on Macroeconomics and Health. (World Health Organisation, 2001)

42. Stanifer, J. W. et al. Traditional medicines and kidney disease in low- and middle-income countries: opportunities and challenges. Semin. Nephrol. 37 245-259 (2017)

43. Stanifer, J. W. et al. Traditional medicine practices among community members with chronic kidney disease in northern Tanzania: an ethnomedical survey. BMC Nephrol. 16, 170 (2015).

44. World Health Organisation. WHO traditional medicine strategy: 2014-2023. (World Health Organisation, 2013).

45. Doku, D. T., Bhutta, Z. A. \& Neupane, S. Associations of women's empowerment with neonatal, infant and under-5 mortality in low- and/middle-income countries: meta-analysis of individual participant data from 59 countries. BMJ Glob. Health 5, e001558 (2020).
46. Langer, A. et al. Women and health: the key for sustainable development. Lancet 386, 1165-1210 (2015).

This article outlines the importance of women's health and women's rights for health and well-being.

47. UN Women. Progress on the Sustainable Development Goals: The Gender Snapshot 2019, https:/ www.unwomen.org/en/digital-library/publications/ 2019/09/progress-on-the-sustainable-development goals-the-gender-snapshot-2019 (2019)

48. Murphy, A et al. The household economic burden of non-communicable diseases in 18 countries. BMJ Glob. Health 5, e002040 (2020).

49. Droti, B., O'Neill, K. P., Mathai, M., Yao Tsidi Dovlo, D. $\&$ Robertson, J. Poor availability of essential medicines for women and children threatens progress towards Sustainable Development Goal 3 in Africa. BMJ Glob. Health 4, e001306 (2019).

50. Orubu, E. S. F., Robert, F. O., Samuel, M. \& Megbule, D. Access to essential cardiovascular medicines for children: a pilot study of availability, price and affordability in Nigeria. Health Policy Plan. 34 iii20-iii26 (2019)

51. World Health Organisation. World Health Statistics 2019: monitoring health for the SDGs, https:/ www.who.int/gho/publications/world_health_statistics/ 2019/en/ (2019)

52. Institute for Health Metrics and Evaluation. Maternal Health Atlas https://maternalhealthatlas.org (2020).

53. Collins, T. et al. Addressing NCDs: a unifying agenda for sustainable development Glob. Public Health 13 1152-1157 (2018)

54. Low Birth Weight and Nephron Number Working Group. The impact of kidney development on the life course: a consensus document for action. Nephron 136, 3-49 (2017).

This article outlines the importance of developmenta programming within the context of the health-care system and public health strategies to reduce the risk of CKD in future generations.

55. Ulasi, I. Gender bias in access to healthcare in Nigeria: a study of end-stage renal disease. Trop. Doct. 38 50-52 (2008)

56. Shaikh, M. et al. Utilization, costs, and outcomes fo patients receiving publicly funded hemodialysis in India. Kidney Int. 94, 440-445 (2018).

57. Morton, R. L. et al. The impact of social disadvantage in moderate-to-severe chronic kidney disease: an equityfocused systematic review. Nephrol. Dial. Transpl. $\mathbf{3 1}$ 46-56 (2016)

58. Hogan J et al. Gender disparities in access to pediatric renal transplantation in Europe: data from the ESPN/ERA-EDTA registry. Am. J. Transpl. 16, 2097-2105 (2016)

59. Moazam, F. Bioethics and Organ Transplantation in a Muslim Society (Indiana University Press, 2006).

60. Clark, $\mathrm{H}$. et al. A future for the world's children? A WHO-UNICEF-lancet commission. Lancet 395 605-658 (2020).

This report highlights the importance of optimizing child health and respecting children's rights for future health and well-being.

61. World Health Organisation. Global Strategy for Women's, Children's and Adolescents Health 2016-2030. (World Health Organisation, 2015).

62. UNICEF. Child Protection from Violence, Exploitation and Abuse, https://www.unicef.org/protection/57929 child_labour.html (2017).

63. Laster Pirtle, W. N. Racial capitalism: a fundamenta cause of novel coronavirus (COVID-19) pandemic inequities in the United States. Health Educ. Behav. 47, 504-508 (2020)

64. Komenda, P et al. The prevalence of CKD in rural Canadian indigenous peoples: results from the first nations community based screening to improve kidney health and prevent dialysis (FINISHED) screen, triage, and treat program. Am. J. Kidney Dis. 68, 582-590 (2016).

65. Caskey, F. \& Dreyer, G. Kidney Health Inequalities in the UK. An Agenda for Change (Kidney Research UK, Peterborough, UK, 2019).

This report demonstrates important persistent inequities in access to care within a health system with universal health coverage.

66. Vart, P., Gansevoort, R. T., Crews, D. C., Reijneveld, S. A \& Bultmann, U. Mediators of the association between low socioeconomic status and chronic kidney disease in the United States. Am. J. Epidemiol. 181, 385-396 (2015).

67. International Society of Nephrology. Global Kidney Health Atlas: a report by the International Society of
Nephrology on the Current State of Organization and Structures for Kidney Care Across the Globe. https:/ www.theisn.org/initiatives/global-kidney-health-atlas/ (2017).

This report highlights global inequities in access to kidney care across the health-care system

68. International Society of Nephrology. Global Kidney Health Atlas: A Report by the International Society of Nephrology on the Global Burden of End-stage Kidney Disease and Capacity for Kidney Replacement Therapy and Conservative Care Across World Countries and Regions. https://www.theisn.org/initiatives/globalkidney-health-atlas/ (2019).

This report highlights global inequities in accesss to care for kidney failure

69. Luyckx, V. A., Miljeteig, I., Ejigu, A. M. \& Moosa, M. R. Ethical challenges in the provision of dialysis in resource-constrained environments. Semin. Nephrol. 37, 273-286 (2017)

This article highlights the ethical dilemmas raised by global inequities in access to kidney care

70. Niessen, L W. et al. Tackling socioeconomic inequalities and non-communicable diseases in low-income and middle-income countries under the Sustainable Development agenda. Lancet 391, 2036-2046 (2018).

71. Ataguba, J. E., Day, C. \& McIntyre, D. Explaining the role of the social determinants of health on health inequality in South Africa. Glob. Health Action 8 , 28865 (2015)

72. Mumford, V. et al. Measuring the financial and productivity burden of paediatric hospitalisation on the wider family network. J. Paediatr. Child. Health 54, 987-996 (2018)

73. Stutzin Donoso, F. Chronic disease as risk multiplier for disadvantage. J. Med. Ethics 44, 371-375 (2018)

74. Morton, R. L. et al. Impact of CKD on household income. Kidney Int. Rep. 3, 610-618 (2018).

75. Verguet, S., Memirie, S. T. \& Norheim, O. F. Assessing the burden of medical impoverishment by cause: a systematic breakdown by disease in Ethiopia. BMC Med. 14, 164 (2016).

This study highlights the vulnerability of households with low income to catastrophic health expenditure.

76. Kankeu, H. T., Saksena, P., Xu, K. \& Evans, D. B. The financial burden from non-communicable diseases in low- and middle-income countries: a literature review. Health Res. Policy Syst. 11, 31 (2013).

77. Das, J., Woskie, L., Rajbhandari, R., Abbasi, K $\&$ Jha, A. Rethinking assumptions about delivery of healthcare: implications for universal health coverage. BMJ 361, k1716 (2018).

78. Agyepong, I. A. Universal health coverage: breakthrough or great white elephant? Lancet 392, 2229-2236 (2018).

79. Kruk, M. E. et al. Mortality due to low-quality health systems in the universal health coverage era: a systematic analysis of amenable deaths in 137 countries. Lancet 392, 2203-2212 (2018). This study emphasizes the urgent need to improve quality of care to reduce unecessary deaths in low- and middle-income countries.

80. Marsh, A. D. et al. Effective coverage measurement in maternal, newborn, child, and adolescent health and nutrition: progress, future prospects, and implications for quality health systems. Lancet Glob. Health $\mathbf{8}$ e730-e736 (2020).

81. Savla, D., Chertow, G. M., Meyer, T. \& Anand, S Can twice weekly hemodialysis expand patient access under resource constraints? Hemodial. Int. 21 , 445-452 (2017)

82. Levin, A. et al. Global kidney health 2017 and beyond a roadmap for closing gaps in care, research, and policy. Lancet 390, 1888-1917 (2017). This article outlines a global roadmap to reduce the global burden of CKD.

83. Bradshaw, C. et al. Early detection of chronic kidney disease in low-income and middle-income countries: development and validation of a point-of-care screening strategy for India. BMJ Glob. Health $\mathbf{4}$ e001644 (2019)

84. Luyckx, V. A. et al. Reducing major risk factors for chronic kidney disease. Kidney Int. Suppl. 7, 71-87 (2017).

85. Vanholder, R. et al. Reducing the costs of chronic kidney disease while delivering quality health care: a call to action. Nat. Rev. Nephrol. 13, 393-409 (2017).

This paper reviews costs across the spectrum of CKD and examines strategies to reduce costs through early disease detection and prevention of kidney disease progression. 
86. Teerawattananon, Y. et al. Dispelling the myths of providing dialysis in low- and middle-income countries. Nat. Rev. Nephrol. https://doi.org/10.1038/s41581 020-00346-7 (2020)

87. REN21. Renewables 2020 Global Status Report. (REN21, 2020).

88. Bowe, B. et al. Estimates of the 2016 global burden of kidney disease attributable to ambient fine particulate matter air pollution. BMJ Open 9 , e022450 (2019)

89. Bragg-Gresham, J. et al. County-level air quality and the prevalence of diagnosed chronic kidney disease in the US Medicare population. PLoS One 13, e0200612 (2018).

90. Bowe, B., Xie, Y., Yan, Y. \& Al-Aly, Z. Burden of causespecific mortality associated with PM2.5 air pollution in the United States. JAMA Netw. Open 2, e 1915834 (2019).

91. Bowe, B. et al. Associations of ambient coarse particulate matter, nitrogen dioxide, and carbon monoxide with the risk of kidney disease: a cohort study. Lancet Planet. Health 1, e267-e276 (2017)

92. Health Effects Institute. State Global Air /2019: A Special Report on Global Exposure to Air Pollution and Its Disease Burden. (Health Effects Institute, 2019).

93. Prüss-Ustün, A. et al. Environmental risks and noncommunicable diseases. BMJ 364, 1265 (2019).

94. Samet, J. M., Burke, T. A. \& Goldstein, B. D. The Trump administration and the environment heed the science. N. Engl. J. Med. 376, 1182-1188 (2017).

95. Landrigan, P. J. et al. The Lancet Commission on pollution and health. Lancet 391, 462-512 (2018).

96. Shakil, M. H., Munim, Z. H., Tasnia, M. \& Sarowar, S COVID-19 and the environment: a critical review and research agenda. Sci. Total. Environ. 745, 141022 (2020).

97. Global Health Data Exchange Institute for Health Metrics and Evaluation. Global Health Data Exchange http://ghdx. healthdata.org/gbd-results-tool (2017).

98. Xu, X. Nie, S., Ding, H. \& Hou, F. F. Environmental pollution and kidney diseases. Nat. Rev. Nephrol. 14, 313-324 (2018)

99. Stanifer, J. W. et al. Perfluorinated chemicals as emerging environmental threats to kidney health: a scoping review. Clin. J. Am. Soc. Nephrol. 13, 1479-1492 (2018)

100. Garcia-Garcia, G. \& Jha, V. \& World Kidney Day Steering, C. CKD in disadvantaged populations. Kidney Int. 87, 251-253 (2015).

101. Jayasumana, C. et al. Chronic interstitial nephritis in agricultural communities: a worldwide epidemic with social, occupational and environmental determinants. Nephrol. Dial. Transpl. 32, 234-241 (2017).

102. Sanders, A. P. et al. Combined exposure to lead, cadmium, mercury, and arsenic and kidney health in adolescents age 12-19 in NHANES 2009-2014. Environ. Int. 131, 104993 (2019).

103. Johnson, R. J. et al. Metabolic and kidney diseases in the setting of climate change, water shortage, and survival factors. J. Am. Soc. Nephrol. 27, 2247-2256 (2016)

104. Barraclough, K. A., Blashki, G. A., Holt, S. G. \& Agar, J. W. M. Climate change and kidney disease threats and opportunities. Kidney Int. 92, 526-530 (2017).

105. Johnson, R. J. \& Sanchez-Lozada, L. G. Chronic kidney disease: Mesoamerican nephropathy - new clues to the cause. Nat. Rev. Nephrol. 9, 560-561 (2013).

106. Nerbass, F. B. \& Pecoits-Filho, R. Can your work affect your kidney's health? Rev. Environ. Health 34 441-446 (2019).

107. Lempert, K. D. \& Kopp, J. B. Renal failure patients in disasters. Disaster Med. Public Health Prep. 13, 782-790 (2019)

108. Barraclough, K. A. \& Agar, J. W. M. Green nephrology. Nat. Rev. Nephrol. 16, 257-268 (2020). This article reviews opportunities in nephrology to protect the environment.

109. Huff, C. How artificial kidneys and miniaturized dialysis could save millions of lives. Nature 579, 186-188 (2020).

110. Vanholder, R., Lameire, N., Annemans, L. \& Van Biesen, W. Cost of renal replacement: how to help as many as possible while keeping expenses reasonable? Nephrol. Dial. Transpl. 31, 1251-1261 (2016).

111. Wieringa, F. P. \& Sheldon, M. The Kidney Health Initiative innovation roadmap for renal replacement therapies: building the yellow brick road, while updating the map. Artif. Organs 44, 111-122 (2020).
112. UNICEF. The State of the World's Children 2019. Children, Food and Nutrition: Growing Well in a Changing World. (UNICEF, 2019).

113. Harding, K. L., Aguayo, V. M. \& Webb, P. Factors associated with wasting among children under five years old in South Asia: implications for action. PLoS One 13, e0198749 (2018).

114. Rana, M. J. \& Goli, S. Does planning of births affect childhood undernutrition? Evidence from demographic and health surveys of selected South Asian countries. Nutrition 47, 90-96 (2018).

115. McGovern, M. E., Krishna, A., Aguayo, V. M. \& Subramanian, S. V. A review of the evidence linking child stunting to economic outcomes. Int. J. Epidemiol. 46, 1171-1191 (2017)

116. World Health Organization. Obesity and Overweight: Key Facts, https://www.who.int/en/news-room/ fact-sheets/detail/obesity-and-overweight (2018).

117. Fox, A., Feng, W. \& Asal, V. What is driving global obesity trends? Globalization or "modernization"? Global. Health 15, 32 (2019).

118. Gutierrez, O. M. Contextual poverty, nutrition, and chronic kidney disease. Adv. Chronic Kidney Dis. 22 31-38 (2015)

119. D'Agati, V. D. et al. Obesity-related glomerulopathy: clinical and pathologic characteristics and pathogenesis. Nat Rev Nephrol 12, 453-471 (2016).

120. He, F. J., Pombo-Rodrigues, S. \& Macgregor, G. A Salt reduction in England from 2003 to 2011: its relationship to blood pressure, stroke and ischaemic heart disease mortality. BMJ Open 4, e004549 (2014).

121. Colchero, M. A., Rivera-Dommarco, J., Popkin, B. M. \& Ng, S. W. In Mexico, evidence of sustained consumer response two years after implementing a sugarsweetened beverage tax. Health Aff. 36, 564-571 (2017).

122. Downs, S. M. et al. The impact of policies to reduce trans fat consumption: a systematic review of the evidence. Curr. Dev. Nutr. 1, cdn. 117.000778 (2017).

123. Huang, L. et al. Effect of dose and duration of reduction in dietary sodium on blood pressure levels: systematic review and meta-analysis of randomised trials. $B M J$ 368, m315 (2020)

124. Watkins, D. A., Olson, Z. D., Verguet, S., Nugent, R. A $\&$ Jamison, D. T. Cardiovascular disease and impoverishment averted due to a salt reduction policy in South Africa: an extended cost-effectiveness analysis. Health Policy Plan. 31, 75-82 (2016).

125. UNICEF. Progress on household drinking water sanitation and hygiene, 2000-2017. (UNICEF, New York, 2019).

126. UNICEF. Drinking water, sanitation and hygiene in schools: global baseline report 2018. (UNICEF, New York, 2018).

127. Augsburg, B. \& Rodriguez-Lesmes, P. A. Sanitation and child health in India. World Dev. 107, 22-39 (2018).

128. Garcia Garcia, G. Poverty: the common denominator of CKD's global threat. MEDICC Rev. 16, 83 (2014).

129. Brunner, E. J., Jones, P. J., Friel, S. \& Bartley, M. Fish, human health and marine ecosystem health: policies in collision. Int. J. Epidemiol. 38, 93-100 (2009)

130. St-Denis, X. Sociodemographic determinants of occupational risks of exposure to COVID-19 in Canada. Can. Rev. Sociol. 57, 399-452 (2020).

131. Nugent, R. et al. Investing in non-communicable disease prevention and management to advance the Sustainable Development Goals. Lancet 391 , 2029-2035 (2018).

132. United Nations. Sustainable Development Goals Knowledge Platform, https://sustainabledevelopment. un.org (2020).

133. Xu, K. et al. Public Spending on Health: A Closer Look at Global Trends (World Health Organisation, 2018)

134. Stenberg, K. et al. Financing transformative health systems towards achievement of the health Sustainable Development Goals: a model for projected resource needs in 67 low-income and middle-income countries. Lancet Glob. Health 5, e875-e887 (2017).

135. World Health Organization. Saving lives, Spending Less: a Strategic Response to Noncommunicable Diseases, https://www.who.int/ncds/management ncds-strategic-response/en/ (2018)

136. Stevenson, M. et al. Land use, transport, and population health: estimating the health benefits of compact cities. Lancet 388, 2925-2935 (2016).

137. Schmidt, H., Gostin, L. O. \& Emanuel, E. J. Public health, universal health coverage, and Sustainable Development Goals: can they coexist? Lancet 386, 928-930 (2015).
138. Kickbusch, I., Allen, L. \& Franz, C. The commercial determinants of health. Lancet Glob. Health 4 e895-e896 (2016)

139. van der Tol, A., Lameire, N., Morton, R. L., Van Biesen, W. \& Vanholder, R. An international analysis of dialysis services reimbursement. Clin. J. Am. Soc. Nephrol. 14, 84-93 (2019).

140. Van Biesen, W. et al. Considerations on equity in management of end-stage kidney disease in lowand middle-income countries. Kidney Int. Suppl. 10 e63-e71 (2020).

141. Thammatacharee, N., Mills, A., Nitsch, D. \& Lumpaopong, A. The changing patterns of access overtime to the renal replacement therapy programme in Thailand. Health Policy Plan. 35, 1-6 (2020).

142. Johnson, D. W. \& Teitelbaum, I. Sustainable, affordable, quality dialysis for universal kidney care. thelancet.com https://www.thelancet.com/campaigns/kidney/updates/ sustainable-dialysis (2017)

143. Ministerio de Salud y Protección Social. Cuenta de Alto Costo. https://cuentadealtocosto.org/site/ quienes-somos/ (2016)

144. Sociedad Latinoamericana de Nefrología e Hipertensión. Reporte 2018 Montevideo.: Registro Latinoamericano de Diálisis y Trasplante Renal. (Sociedad Latinoamericana de Nefrología e Hipertensión, 2019).

145. Alvis-Zakzuk, J. et al. Out-of-pocket and catastrophic health expenditure in households of Cartagena, Colombia. Rev. Salud Pública https://doi.org/ 10.15446/rsap.v20n5.61403 (2018).

146. Lopera-Median, M. Chronic kidney disease in Colombia: health needs and response of the general system of social security in health. Rev. Gerenc. Polit. Salud 15, 212-233 (2016).

147. Moosa, M. R., Maree, J. D., Chirehwa, M. T. \& Benatar, S. R. Use of the 'Accountability for Reasonableness' approach to improve fairness in accessing dialysis in a middle-income country. PLoS One 11, e0164201 (2016).

148. Davids, M. R. et al. South African renal registry. Annual Report 2017 (South Africa, 2019).

149. Ministry of Health Kenya. Government Steps up Fight Against Kidney Diseases http://www.health.go.ke/ government-steps-up-fight-against-kidney-diseases/ (2017).

150. Mshumpela, C. N., Etheredge, H. R., Fabian, J, Loveland, J. \& Botha, J. Access to renal replacement therapy in South Africa - a cry for action. Transplantation 104, 1109-1111 (2020).

151. Chadban, S. et al. The CARI guidelines. Costeffectiveness and socioeconomic implications of prevention and management of chronic kidney disease in type 2 diabetes. Nephrology 15, S195-S203 (2010).

152. Mendu, M. L. et al. Federal funding for kidney disease research: a missed opportunity. Am. J. Public Health 106, 406-407 (2016).

153. Ojo, A. Addressing the global burden of chronic kidney disease through clinical and translational research. Trans. Am. Clin. Climatol. Assoc. 125, 229-243 (2014).

154. Reidpath, D. D. \& Allotey, P. The problem of 'trickledown science' from the Global North to the Global South. BMJ Glob. Health 4, e001719 (2019).

155. Ene-lordache, B. et al. Chronic kidney disease and cardiovascular risk in six regions of the world (ISNKDDC): a cross-sectional study. Lancet Glob. Health 4 e307-e319 (2016)

156. Joshi, R., John, O. \& Jha, V. The potential impact of public health interventions in preventing kidney disease. Semin. Nephrol. 37, 234-244 (2017).

157. Victor, R. G. et al. Sustainability of blood pressure reduction in black barbershops. Circulation 139, 10-19 (2019).

158. Melcher, M. L. et al. Kidney transplant chains amplify benefit of nondirected donors. JAMA Surg. 148, 165-169 (2013).

159. WareJoncas, Z. et al. Precision gene editing technology and applications in nephrology. Nat. Rev. Nephrol. 14 663-677 (2018)

160. Gopichandran, V. et al. Developing the ethics of implementation research in health. Implement. Sci. 11, 161 (2016).

161. World Health Organization. Regional Office for South East Asia. Approaches to establishing country-level multisectoral coordination mechanisms for the prevention and control of noncommunicable diseases. (World Health Organisation, 2015).

162. Shaikh, S. et al. The mangnitude and determinants of violence against healthcare workers in Pakistan. BMJ Glob. Health 5, e002112 (2020). 
163. Mercy, J. A. et al. in Injury Prevention and Environmental Health 3rd Edn Ch. 5 (eds Mock, C. N. et al.) (The International Bank for Reconstruction and Development/The World Bank, 2017).

164. Gates, S., Hegre, H., Nygard, H. M. \& Strand, H. Development consequences of armed conflict. World Dev. 40, 1713-1722 (2012).

165. Leaning, J. \& Guha-Sapir, D. Natural disasters, armed conflict, and public health. N. Engl. J. Med. 369, 1836-1842 (2013).

166. Pettersson, T. \& Eck, K. Organized violence, 1989-2017. J. Peace Res. 55, 535-547 (2018)

167. Jawad, M., Vamos, E. P., Najim, M., Roberts, B. \& Millett, C. Impact of armed conflict on cardiovascular disease risk: a systematic review. Heart 105 , 1388-1394 (2019)

168. Stewart, I. J. et al. Retrospective analysis of long-term outcomes after combat injury: a hidden cost of war. Circulation 132, 2126-2133 (2015).

169. Mesic, E., Aleckovic-Halilovic, M., Tulumovic, D. \& Trnacevic, S. Nephrology in Bosnia and Herzegovina: impact of the 1992-95 war. Clin. Kidney J. 11, 803-809 (2018)

170. Almassri, I. \& Sekkarie, M. Cases of thallium intoxication in Syria: a diagnostic and a therapeutic challenge. Avicenna J. Med. 8, 78-81 (2018).

171. Isreb, M. A. et al. The effect of war on Syrian refugees with end-stage renal disease. Kidney Int. Rep. 2, 960-963 (2017)

172. Van Biesen, W., Vanholder, R., Ernandez, T., Drewniak, D. \& Luyckx, V. Caring for migrants and refugees with end-stage kidney disease in Europe. Am. J. Kidney Dis. 71, 701-709 (2017)

173. Van Biesen, W. et al. Renal replacement therapy for refugees with end-stage kidney disease: an international survey of the nephrological community. Kidney Int. Suppl. 6, 35-41 (2016).

174. Gursu, M. et al. Hemodialysis experience of a large group of syrian refugees in Turkey: all patients deserve effective treatment. Kidney Blood Press. Res. 44, 43-51 (2019).

175. Karah, N. et al. Dialysis therapy for Syrian refugees in Lebanon: a call for action. Bull. World Health Organ. 96, 370 (2018)

176. Cervantes, L., Grafals, M. \& Rodriguez, R. A. The United States needs a national policy on dialysis for undocumented immigrants with ESRD. Am. J. Kidney Dis. 71, 157-159 (2018)

177. Topf, J. M. Introduction: social media and medical education come of age. Semin. Nephrol. 40, 247-248 (2020).

178. Alexander, P. E. et al. COVID-19 coronavirus research has overall low methodological quality thus far: case in point for chloroquine/hydroxychloroquine. J. Clin. Epidemiol. 123, 120-126 (2020).

179. Mesmar, S. et al. The impact of digital technology on health of populations affected by humanitarian crises: recent innovations and current gaps. J. Public Health Policy 37, 167-200 (2016).

180. Labrique, A. B. et al. Best practices in scaling digital health in low and middle income countries. Global Health 14, 103 (2018).

181. Khoury, M. J. \& Galea, S. Will precision medicine improve population health? JAMA 316, 1357-1358 (2016).

182. Van Biesen, W., Decruyenaere, J., Sideri, K., Cockbain, J. \& Sterckx, S. Remote digital monitoring of medication intake: methodological, medical, ethical and legal reflections. Acta Clin. Belg. https:// doi.org/10.1080/17843286.2019.1708152 (2019).

183. Naidoo, R. \& Fisher, B. Reset sustainable development goals for a pandemic world. Nature 583, 198-201 (2020).

184. Figueroa, J. F., Frakt, A. B. \& Jha, A. K. Addressing social determinants of health: time for a polysocial risk score. JAMA 323, 1553-1554 (2020).

185. Htay, H. et al. Global access of patients with kidney disease to health technologies and medications: findings from the Global Kidney Health Atlas project. Kidney Int. Suppl. 8, 64-73 (2018).

186. Galtung, J. Violence, peace, and peace research J. Peace Res. 6, 167-191 (1969).
187. Farmer, P. Pathologies of power: rethinking health and human rights. Am. J. Public Health 89, 1486-1496 (1999).

188. Commission on Social Determinants of Health. Closing the gap in a generation: health equity through action on the social determinants of health. Final Report of the Commission on Social Determinants of Health. (World Health Organisation, Geneva, 2008).

189. Marmot, M. et al. Fair Society Healthy Lives: Strategic Review of Health Inequalities in England Post-2010. (The Marmot Review, 2010).

190. Baqui, P., Bica, I., Marra, V., Ercole, A. \& van der Schaar, M. Ethnic and regional variations in hospital mortality from COVID-19 in Brazil: a crosssectional observational study. Lancet Glob. Health 8 e1018-e1026 (2020).

191. Aldridge, R. W. et al. Black, Asian and Minority Ethnic groups in England are at increased risk of death from COVID-19: indirect standardisation of NHS mortality data. Wellcome Open Res. 5, 88 (2020)

192. Tai, D. B. G., Shah, A., Doubeni, C. A., Sia, I. G. \& Wieland, M. L. The disproportionate impact of COVID-19 on racial and ethnic minorities in the United States. Clin. Infect. Dis. https://doi.org/10.1093/cid/ ciaa815 (2020).

193. D'Marco, L. et al. Coronavirus disease 2019 in chronic kidney disease. Clin. Kidney J. 13, 297-306 (2020).

194. Garcia-Garcia, G. et al. Chronic kidney disease of unknown cause in Mexico: the case of Poncitlan, Jalisco. Clin. Nephrol. 93, 42-48 (2019).

195. Lozano-Kasten, F., Sierra-Diaz, E., de Jesus Celis-de la Rosa, A., Margarita Soto Gutierrez, M. \& Aaron Peregrina Lucano, A Prevalence of albuminuria in children living in a rura agricultural and fishing subsistence community in Lake Chapala, Mexico. Int. J. Environ. Res. Public Health 14, 1577 (2017)

196. Stong, T. et al. Mercury concentrations in common carp (Cyprinus carpio) in Lake Chapala, Mexico: a lakewide survey. J. Environ. Sci. Health. A Tox. Hazard. Subst. Environ. Eng. 48, 1835-1841 (2013).

197. Inter-American Commission on Human Rights. Resolution 7/2020. Precautionary Measure No. 708-19, http://www.oas.org/en/iachr/decisions/ precautionary.asp (2020)

198. Trasande, L. et al. Methylmercury exposure in a subsistence fishing community in Lake Chapala, Mexico: an ecological approach. Environ. Health 9, 1 (2010).

199. Smpokou, E. T. et al. Environmental exposures in young adults with declining kidney function in a population at risk of Mesoamerican nephropathy. Occup. Environ. Med. 76, 920-926 (2019).

200. Sierra-Diaz, E. et al. Urinary pesticide levels in children and adolescents residing in two agricultural communities in Mexico. Int. J. Environ. Res. Public 16, 562 (2019).

201. Jayasumana, C., Gunatilake, S. \& Senanayake, P. Glyphosate, hard water and nephrotoxic metals: are they the culprits behind the epidemic of chronic kidney disease of unknown etiology in Sri Lanka? Int. J. Environ. Res. Public Health 11, 2125-2147 (2014).

202. Jayasumana, C. et al. Drinking well water and occupational exposure to Herbicides is associated with chronic kidney disease, in Padavi-Sripura, Sri Lanka. Environ. Health 14, 6 (2015)

203. Macedo, E., Rocco, M. V., Mehta, R. \& Garcia-Garcia, G Safe water community project in jalisco, Mexico. Ann. Nutr. Metab. 74, 51-56 (2019).

204. Secretaria de Salud Jalisco. Indicadores de Mortalidad por Enfermedades Infecciosas Intestinales en Menores de 5 años (Secretaria de Salud Jalisco, 2013).

205. Comisión Estatal de Derechos Humanos de Jalisco. Recomendaciones emitidas en 2009. Recomendación 01/2009. (Comisión Estatal de Derechos Humanos de Jalisco, 2009)

206. Jauregui, I. S. Implementan estudio para control de enfermedad renal en Poncitlán. gaceta.udg. $m x$ http:// www.gaceta.udg.mx/implementan-estudio-paracontrol-de-enfermedad-renal-en-poncitlan/ (2019).

207. Habib, Y. Venezuela in the gloom. aldianews.com https://aldianews.com/articles/politics/venezuelagloom/55192 (2019)

208. Médicos por la Salud. Encuesta Nacional de Hospitales - Segundo Boletín Noviembre 2018, https://www.encuestanacionaldehospitales.com/2018 (2018).

209. Pampillón Olmedo, R. \& Zapata Rubio, A. in Expansión (Unidad Editorial Informaciōn Económica S.L., 2019).

210. Nelson, R. M. Venezuela's Economic Crisis: Issues for Congress (Congressional Research Service, 2018).

211. Page, K. R. et al. Venezuela's public health crisis: a regional emergency. Lancet 393, 1254-1260 (2019).

212. Gonzalez-Bedat, M. C., Rosa-Diez, G. \& Ferreira, A El registro Latinoamericano de diálisis y trasplante renal: la importancia del desarrollo de los registros nacionales en Latinoamérica. Nefrol. Latinoamericana 14, 12-21 (2017).

213. Herrera, I. El holocausto de los 3.000 dializados que desaparecieron. Armandolnfo https://armando.info/ Reportajes/DemoPrivado/2498 (2018)

214. Escalona, J. Federacion Médica de Venezuela: Más de 30.000 médicos se han ido de Venezuel. elimpulso.com https://www.elimpulso.com/2019/09/ 12/fmv-30-000-medicos-se-han-ido-de-venezuela$12 \mathrm{sep} /(2019)$.

215. United Nations High Commissioner for Refugees. Syria Emergency, https://www.unhcr.org/syria-emergency. html (2020).

216. Mills, M. Organ trafficking 'booming' in Lebanon as desperate Syrians sell kidneys, eyes: BBC. reuters. com https://www.reuters.com/article/us-mideast-crisis-syriatrafficking/organ-trafficking-booming-in-lebanon-asdesperate-syrians-sell-kidneys-eyes-bbc idUSKBN17S1 V8 (2017).

217. Médecins Sans Frontières. Beyond trauma injuries: one of Syria's neglected health needs. msf.org https:/ www.msf.org/care-kidney-transplant-patients-syria (2019).

\section{Acknowledgements}

The authors are grateful to B. Bikbov (Istituto di Ricerche Farmacologiche Mario Negri IRCCS, Bergamo, Italy) for clarifications regarding data from the Global Burden of Disease studies.

\section{Author contributions}

V.A.L., Z.A.-A., A.K.B., J.F., G.G.-G., A.I., W.v.B. and J.S researched data for the article. V.A.L., A.I., W.v.B. and J.S made substantial contributions to discussions of the content.

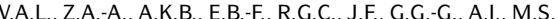
W.v.B. and J.S. wrote the manuscript. V.A.L., Z.A.-A., A.K.B., J.F., G.G.-G., A.I., M.S., W.v.B., I.U., K.Y. and J.S. reviewed or edited the manuscript before submission.

\section{Competing interests}

V.A.L. is an executive Committee Member of the International Society of Nephrology and an editor for Brenner and Rector's "The Kidney" (Elsevier). G.G.-G. has received grant support from CloudCath Inc. and consulting fees from Ellen Medical Devices Pty Ltd. W.v.B. has received speaker fees from Fresenius Medical Care, Baxter Healthcare, Nippro and Gambro, and is vice-chair of EuroPD. The other authors declare no competing interests.

\section{Peer review information}

Nature Reviews Nephrology thanks A. Niang and the other, anonymous, reviewer(s) for their contribution to the peer review of this work.

\section{Publisher's note}

Springer Nature remains neutral with regard to jurisdictional claims in published maps and institutional affiliations.

\section{Supplementary information}

Supplementary information is available for this paper at https://doi.org/10.1038/s41581-020-00363-6.

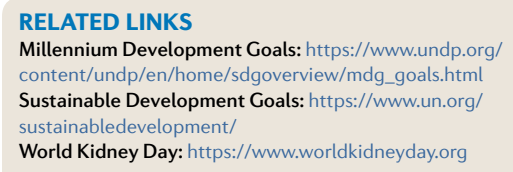

C) Springer Nature Limited 2020, corrected publication 2021 